\title{
Airborne Particles during a Firework Festival in Belvedere M.mo, South-Western Italian Coast
}

\author{
Mariantonia Bencardino ${ }^{*}$, Virginia Andreoli ${ }^{1}$, Jessica Castagna ${ }^{1,2}$, Francesco D'Amore ${ }^{1}$, \\ Valentino Mannarino1, Sacha Moretti1,2, Attilio Naccarato1, Nicola Pirrone ${ }^{3}$, \\ Francesca Sprovieri ${ }^{1}$
}

\author{
${ }^{1}$ CNR-Institute of Atmospheric Pollution, Division of Rende, Cosenza, Italy \\ ${ }^{2}$ Department of Physics, University of Calabria, Cosenza, Italy \\ ${ }^{3}$ CNR-Institute of Atmospheric Pollution, Rome, Italy \\ Email: *bencardino@iia.cnr.it
}

How to cite this paper: Bencardino, M., Andreoli, V., Castagna, J., D'Amore, F., Mannarino, V., Moretti, S., Naccarato, A., Pirrone, N. and Sprovieri, F. (2018) Airborne Particles during a Firework Festival in Belvedere M.mo, South-Western Italian Coast. Open Journal of Air Pollution, 7, 156-180.

https://doi.org/10.4236/ojap.2018.72009

Received: May 14, 2108

Accepted: June 26, 2018

Published: June 29, 2018

Copyright $\odot 2018$ by authors and Scientific Research Publishing Inc. This work is licensed under the Creative Commons Attribution International License (CC BY 4.0).

http://creativecommons.org/licenses/by/4.0/

\begin{abstract}
The effects of a Summer Firework Festival on the air quality were studied for the first time in a rural area of Southern Italy. The case study analyzes the physical-chemical properties of airborne particles collected during the Note di Fuoco (NDF) Festival, which took place in Belvedere M.mo in 2016. The sampling period was peculiar since in one week three different kinds of events have succeeded: three days during the NDF Festival with the concurrence of the festival and the firework displays, one day with the typical street Market involving food stalls and specialty shops, and three days with no specific events, considered as background conditions. Particulate Matter in different two size fractions $\left(P M_{2.5}\right.$ and $\left.P M_{10}\right)$ was simultaneously collected on a daily basis and then chemically analyzed for major and trace metal content as well as for organic and elemental carbon determination. Levels of particles were even below the European air quality limit values. However, the day with the country market and during the three days of the NDF festival, the finer and respirable particulate fraction, $P M_{2.5}$, showed an increase of $46 \%$ and $84 \%$, respectively, over the mean concentration values observed during the background days. Both elemental and organic carbon, even in the finer fraction showed an increment up to $30 \%$. All major, and trace elements were found in higher concentrations during the festival with respect to those recorded in days with no events. In our case study, $\mathrm{K}$ was recognized as the best fireworks tracer because its level doubled during the festival. Typical firework tracers like $\mathrm{Fe}, \mathrm{Ti}, \mathrm{Mn}, \mathrm{Pb}$ and $\mathrm{Sr}$ resulted in greater concentrations, up to $50 \%$.
\end{abstract}

\section{Keywords}

Fireworks, Air Quality, Particulate Matter, Tracers 


\section{Introduction}

Fireworks are products of pyrotechnic industry that are displayed throughout the world to celebrate special events (New Years Eve, National Day) as well as traditional and religious festivals. The scale of fireworks displays can vary from as small as a birthday party up to a national day celebration [1] or one-off worldwide events, such as the millennium celebrations in 2000 [2].

Fireworks displays are becoming more frequent and are increasing in both their number and quality [3]. As an example, the Divali Festival in India [4] [5] [6], the Las Fallas, Valencia, in Spain [7], the Festas in the Maltese archipelago [8], the Lantern Festival in Beijing, China [9], and the Firework Festival in Taiwan [3] consume hundreds of thousands of tons of fireworks and firecrackers every year.

The tradition of fireworks in Italy is quite common with greater emphasis in the Southern regions. Nevertheless, in literature there is only well documented study carried out by Vecchi et al. (2008) [10] focusing on a firework episode in Milan occurring in correspondence of the World Fifa 2006.

Apart from the benefits provided by the splendid scenes of multicolored lights in the sky and the excitement of continuous brittle and resounding firecracker detonations, the burning of fireworks is a source of airborne pollutants, including $\mathrm{O}_{3}$ [11] [12], $\mathrm{SO}_{2}, \mathrm{NO}_{2}, \mathrm{CO}$ and suspended particulate matter [9]. Fireworks consist of gunpowder and some unique chemical substances that give them their color and effect. Some of these substances include $\mathrm{K}, \mathrm{Al}, \mathrm{Ba}, \mathrm{Mn}, \mathrm{Cd}, \mathrm{Cu}, \mathrm{Sr}$, and other heavy metals that are very harmful to human health [7] [10] [13]. The effects of airborne particulate matter on the environment and human health are strongly dependent on their size and chemical composition [14] [15].

The firework-related recreational pollution episodes during a few hours in the year provide an input of metal burden which is carried in initially dense clouds of extremely fine, easily deeply inhalable particles. Such emissions have been proven to be capable of inducing short-term adverse health effects, especially for asthmatic children and other respiratory-sensitive groups of the population [16] [17]. Firework smoke is indeed known to lead to acute eosinophilic pneumonia [18]. Barium-rich aerosols released from fireworks may be responsible for a significant rise in the number of asthma cases [19]. Majorities of barium compounds released by pyrotechnics are water-soluble and thus, bio-available, which may cause even more significant harm [20]. More recently, a positive and significant relationship was found between particulate oxidative burden and trace metals impact of firework-emitted particles on human health [21].

While for Chinese, Japanese and Indian countries there is a quite large amount of literature describing the physico-chemical characteristics of firework particles and their harmful effects of fireworks on the environment and human health, [3] [6] [22] [23] over the Italian region there are few reference studies [10], especially for the southern Italian part, where fireworks festival usually oc- 
cur. To the best of our knowledge, there have been no studies regarding the simultaneous characterization of elemental and carbon content components during a firework festival in Southern Italy. This preliminary study thus provides an opportunity to assess the associated changes in the levels of ambient air pollutants caused by fireworks in a rural area of the south-western Italian coast.

In the complex, this paper reports simultaneous monitoring of 13 elements, as well as Elemental and Organic Carbon (EC and OC) in ambient aerosols collected during the 2016 NDF Festival in the town of Belvedere M.mo, Calabria, South Italy. Relative enhancements of tracer species during the pollution episode were studied, and efforts were made to justify the findings.

\section{Materials and Methods}

\subsection{Sampling Site}

As Figure 1 shows, Belvedere M.mo is a small town in the province of Cosenza, part of the Calabria region of Southern Italy. It is located at $39^{\circ} 37^{\prime}$ north and $15^{\circ} 52^{\prime}$ east on the south-western Italian coast, facing on the western side of the Tyrrhenian Sea. On the eastern side there is indeed a stretch of mountain chain which is part of the Pollino massif running parallel to the west coast. Belvedere M.mo experiences a Mediterranean climate with mean temperatures during winter and summer around $11^{\circ} \mathrm{C}$ and $25^{\circ} \mathrm{C}$, respectively [24]. Belvedere M.mo has a population more than 9 thousand [25] and it is a rural area without any particular anthropogenic local source, being its economy mainly based on commercial and artisanal activities. The territory includes two distinct areas: the medieval village, which stands on a rocky ledge at $150 \mathrm{~m}$ a.s.l. and the most

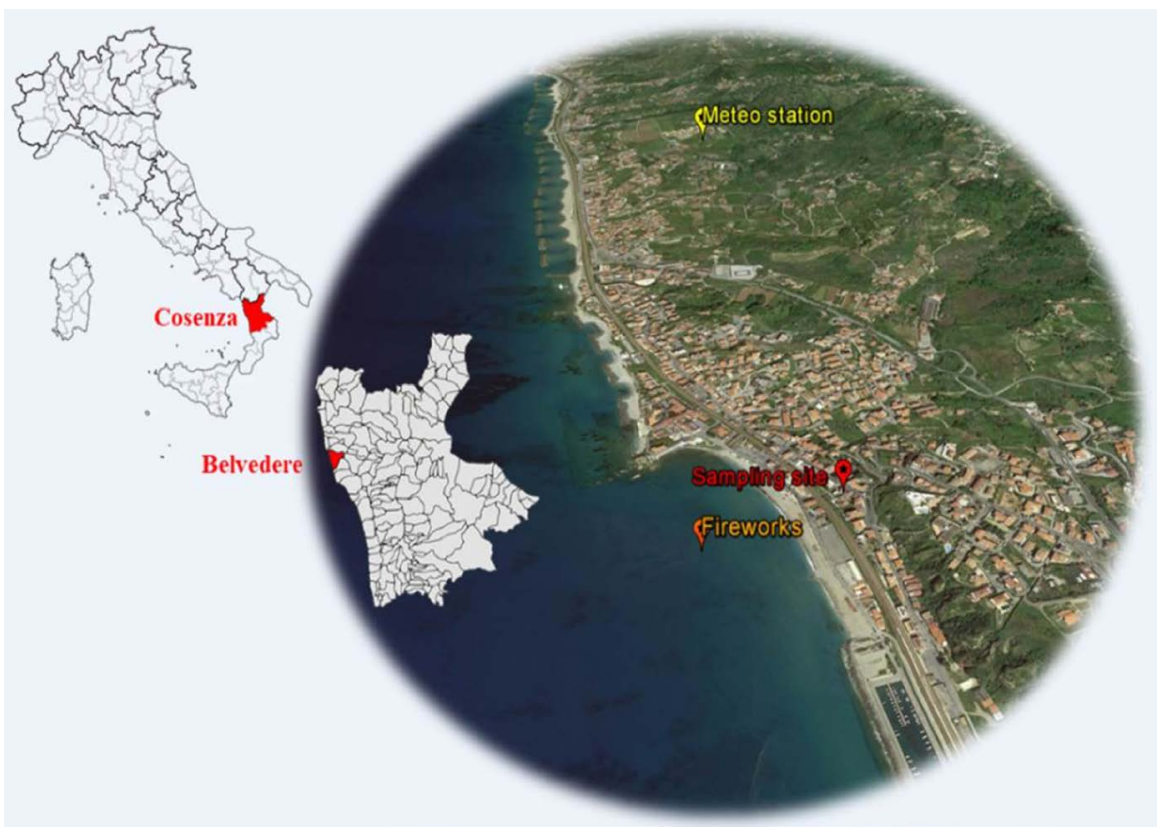

Figure 1. Map showing the contest and location of the Sampling site along with the Meteo station and the little Capo Tirone sea basin where the Firework displays took place. 
properly maritime part, developed on the coast at $5 \mathrm{~m}$ a.s.l., which include various tourist services. Traditionally, each Wednesday morning, the maritime part of Belvedere is interested by a typical street Market (hereafter referred simply to as "Market") that involves many food stalls and specialty shops resulting in a greater flow of cars and trucks. Since 2007, even in the maritime area, and precisely around the facing sea basin known as Capo Tirone, a great and consolidated firework display Festival took place each summer. The Festival, called Note di Fuoco (NDF), is marked by 3 days off celebration including permanent street food cookers, various kind of artistic performances, and ending each night with an exhibition among the best fireworks companies in the world of fire art. Each year multi-launch stations, with large batteries of fires and simultaneous radio-controlled departures, are arranged over the Capo Tirone basin. During the pyrotechnic show, it is possible to admire the explosion of tons of gunpowder in a great choreography of music, lights and colors, with fan flies that reach an amplitude of aerial fire of over 200 meters. The Festival attracts a large number of tourists and curious.

\subsection{Sample Collection}

Aerosol particles were collected by 2 distinct sampling monitors on the roof (15 $\mathrm{m}$ high) of a building in Belvedere M.mo, far about $130 \mathrm{~m}$ from the coastline (see Figure 2). $P M_{10}$ and $P M_{2.5}$ collections were carried out according to European Standards EN-12341:1998 and EN-14907:2005, respectively [26]. Samples were simultaneously collected on $47-\mathrm{mm}$ Whatman quartz microfiber filters, through 2 lower-volume samplers, the Echo PM-Instruments (Tecora), each equipped with the proper $P M_{10}$ and $P M_{2.5}$ inlet, and both operating with a flow rate of about $38 \mathrm{~L} \cdot \mathrm{min}^{-1}$. The samples and blank filters were kept in polyethylene bags before and after sampling until analysis. Before and after sampling collection, each filter was conditioned under constant temperature $\left(25^{\circ} \mathrm{C}\right)$ and relative humidity (50\%) for 24 hours, a then weighed using a micro-balance (Gibertini microcrystal model) with $0.1-\mu$ g sensitivity. All weight measurements were repeated thrice to ensure reliability, and the average was taken to make the consistency in reading. The net weight collected, obtained as the gross (after sampling) minus the tare (before sampling) filter weight, was divided by the collected standardized sampling volume to obtain the corresponding concentration by the gravimetric method. All the procedures were strictly quality-controlled to avoid any possible contamination of the samples. $P M_{10}$ and $P M_{2.5}$ were monitored over a 24-hours sampling period, from the 29 July to the 4 August 2016. The observing sampling week covered the 3-day period of the NDF Festival (29, 30 and 31 July) and a period following the end of the Festival, including 3 days with no specific events and taken as background (1, 2 and 4 August), and 1 day during which the typical country Market took place (3 August). Starting time was set at midnight of each new day and lasted for 24-hours. The systematic sampling plan, and the Identification coding for the days during and after the NDF 


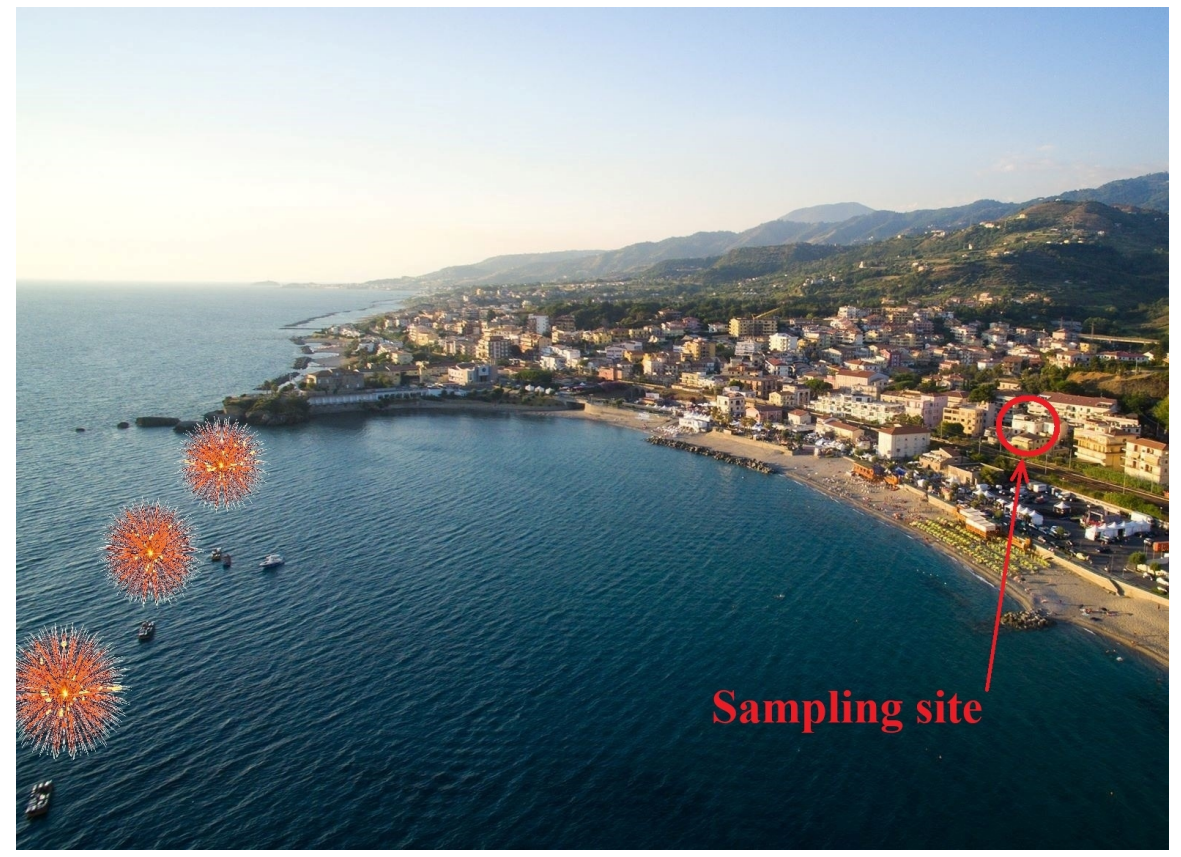

Figure 2. Location of the Sampling site within the little Capo Tirone sea basin where the Firework displays took place.

festival, is presented in Table 1. In total, fourteen samples (seven for $P M_{2.5}$ and seven for $P M_{10}$ ) were collected along with seven blank filters, which were kept in the same condition as the actual samples. During the sampling period, meteorological data, including wind speed and direction, were obtained by the Arpacal weather station $\left(39^{\circ} 38^{\prime} \mathrm{N} 15^{\circ} 51^{\prime} \mathrm{E}\right)$ at about $2 \mathrm{~km}$ northward from the sampling site (see Figure 1). The anemometer is at a height of $12 \mathrm{~m}$ above the ground surface.

\subsection{Analytical Techniques}

\subsubsection{EC/OC Measurements}

The carbonaceous species are operationally classified into organic carbon (OC) and elemental carbon (EC). EC is mainly derived from incomplete combustion of fossil-fuel, biomass burning and other carbon-contained material. It has a long photo-chemical lifetime and this makes it a good indicator of primary anthropogenic air pollution [22] [27]. Organic carbon originates from a variety of processes. It can be released into the atmosphere from anthropogenic (fossil fuel combustion, domestic heating and cooking, industrial processes, biomass burning), and biogenic sources (vegetation, wind-lifted biological particles, fires, emissions from marine environments), as primary OC (POC), or produced within the atmosphere by photo-chemical reactions through gas-to-particle conversion of volatile organic compounds, as secondary OC (SOC) [28] [29]. The concentrations of the carbonaceous species were determined on one punch (area: $1 \mathrm{~cm}^{2}$ ) cut from the quartz fiber filters employed for collecting the 24-h $P M_{10}$ and $P M_{2.5}$ samples. All the filters prior the sampling were pre-fired for $2 \mathrm{~h}$ at $700{ }^{\circ} \mathrm{C}$ in order to remove any residual carbon contamination. The analysis of 
Table 1. Sampling plan and Identification coding for the week of aerosol collection.

\begin{tabular}{lcc}
\hline Sample ID & Influencing Event & Day of Sampling \\
\hline NDF_2907 & 1st day of Note Di Fuoco & 29 July 2016 \\
NDF_3007 & 2nd day of Note Di Fuoco & 30 July 2016 \\
NDF_3107 & 3rd day of Note Di Fuoco & 31 July 2016 \\
BKG_0108 & 1st Background day with No event & 1 August 2016 \\
BKG_0208 & 2nd Background day with No event & 2 August 2016 \\
MKT_0308 & Market day & 3 August 2016 \\
BKG_0408 & 3nd Background day with No event & 4 August 2016 \\
\hline
\end{tabular}

Total Carbon ( $\mathrm{TC}=\mathrm{OC}+\mathrm{EC})$, OC, and EC was performed by the thermo-optical method (TOT) using a Sunset Laboratory OC/EC analyzer (Sunset Laboratory, Tigard, OR, USA), implementing the EUSAAR-II temperature protocol [30]. This thermal protocol, characterized by a transmittance optical correction for pyrolysis, has been recently selected as the European standard thermal protocol for the measurements of TC, OC and EC in $P M$ samples (EN 16909:2017) [26]. To ensure the accuracy of the OC and EC analysis, the analyzer was calibrated using a sucrose solution as an external standard. Blank filters, from each of the three observed events, were also analyzed for correcting the measured concentrations. EC concentrations observed in blank filters were negligible; however, contamination was observed for OC with an average correction that was about $7 \%$. In this study, the SOC concentration was additionally quantified using the minimum OC/EC ratio methodology proposed by [31]-[37].

\subsubsection{Multielement Analysis}

$P M_{10}$ and $P M_{2.5}$ filters were digested by using a microwave-assisted protocol in accordance to the EN 14902:2005 standard [26]. This approach is better than the traditional heating procedures, involving heat convection or diffusion phenomena because increase the digestion efficiency and minimize the sample contamination. Each filter was transferred to TFM (tetrafluoromethoxil) vessels with 8 $\mathrm{mL}$ of $\mathrm{HNO}_{3}, 2 \mathrm{~mL}$ of $\mathrm{H}_{2} \mathrm{O}_{2}$ and $0.2 \mathrm{~mL}$ of HF. The vessels were placed in the microwave oven and digested using a three-step temperature-time program in which the temperature was increased to $180{ }^{\circ} \mathrm{C}$ in $15 \mathrm{~min}$, then to $220^{\circ} \mathrm{C}$ in 10 min and hold at this temperature for $10 \mathrm{~min}$. Following digestion, the analysis was carried out by Inductively Coupled Plasma Mass Spectrometry, ICP-MS, (7500CE, Agilent) for the elemental content determination. The analytical batch consisted of a set of calibration standards, which were analyzed at the beginning of the run, samples, and a minimum of three blank filter samples whose values were subtracted from each sample. A mid-range calibration standard was measured after every 20 samples to assess instrumental drift throughout the run. A six-point calibration curve covering the range of $0.1-1000 \mu \mathrm{g} \cdot \mathrm{L}^{-1}$ was used for quantitative analysis. Internal standardization was performed by on-line addi- 
tion of a $200 \mu \mathrm{g} \cdot \mathrm{L}^{-1} \mathrm{Rh}$ solution through a Y-connector. The use of internal standard quantitation allows satisfactory and repeatable results to be obtained by ICP-MS, even if instrumental instabilities are observed. The following elements were investigated: $\mathrm{Na}, \mathrm{Al}, \mathrm{K}, \mathrm{Fe}, \mathrm{Ca}, \mathrm{Mg}, \mathrm{Ti}, \mathrm{V}, \mathrm{Cu}, \mathrm{Ba}, \mathrm{Mn}, \mathrm{Pb}, \mathrm{Sr}, \mathrm{Ni}$.

\section{Results and Discussion}

\subsection{Meteorological Field Analysis and Characterization}

\subsubsection{Synoptic Scale}

The sampling site is located within the Mediterranean basin. Belvedere M.mo thus experiences meteorological conditions in line with the typical Mediterranean climate [38]. Exactly, we registered no rain in our summer sampling period with high temperature (means around $26^{\circ} \mathrm{C}$ ) as those typically recorded during the warmest month of July and August in the Mediterranean region [39]. The synoptic chart of NCEP-based 925 mbar geopotential heights $(\mathrm{m})$ during our sampling periods (from 29 Jul until $4 \mathrm{Aug}$ ) shows the persistence of an irregular Anticyclone vortex which spans from the Algerian-Libyan desert to the Île-de France and the North of the Alpine region (see Figure A1 in Supplemental section). When the Libyan anticyclone invades the Mediterranean basin, there is a general subsidence over the region, with a diffusive tropospheric adiabatic warming thus favoring a general accumulation of aerosol in the boundary layer.

\subsubsection{Local Scale}

The local wind field conditions were equally important in affecting aerosol content at our sampling site. Being our sampling site located in a coastal area, the land-sea breeze played an important role in the variations of the aerosol loading over the site. Over the whole week of our observations, wind speed showed a diurnal variation with comparative lower values in the evening, around $1 \mathrm{~ms}^{-1}$, in respect to those recorded during the morning that were double in intensity, around $2 \mathrm{~ms}^{-1}$. Specifically, during the evening, the wind intensity ranged from 0.1 to $2.6 \mathrm{~ms}^{-1}$, characterized over the $73 \%$ by "Light Air" and for the $25 \%$ of the cases by "Light breeze", expressed as Beaufort scale [40]. The wind intensity was stronger during daylight with values from 0.1 to $3.6 \mathrm{~ms}^{-1}$ with a major frequency of the higher scales: $22 \%$ of "Light Air", $73 \%$ of "Light breeze" and also a $4 \%$ of "Gentle Breeze". The wind rose analysis (see Figure 3) of all the days during our period of study shows that most winds were onshore (sea breeze) during the day, and then changed direction to blow offshore (land breeze) during the night and till early morning. The prevailing surface winds blow from sea in south-west and west direction. Exactly the opposite direction was observed during nighttime, mainly from land in northeast and east direction, but with weaker wind speed. Being the firework displays arranged around midnight, with the above mentioned wind prevailing direction during nighttime, there could be a reason to suppose that aerosol particle load emitted from fireworks was underestimated since, in respect to our point of sampling, it was measured upwind. However, the vicinity of the sampling site to the coast, where fireworks have been displayed, 


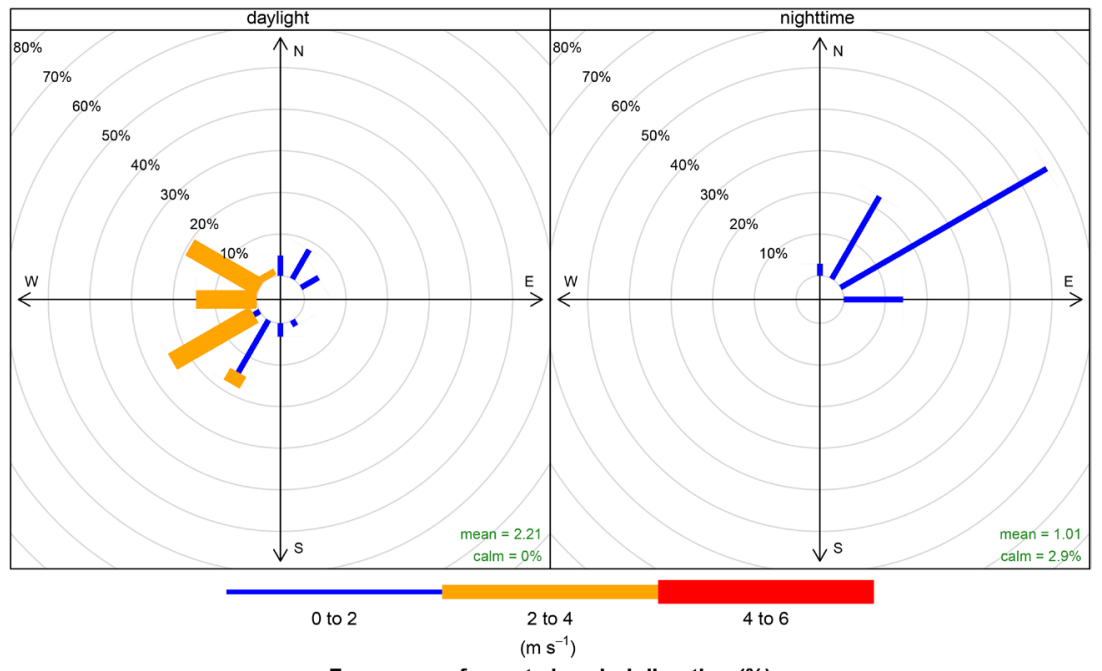

Frequency of counts by wind direction (\%)

(a)

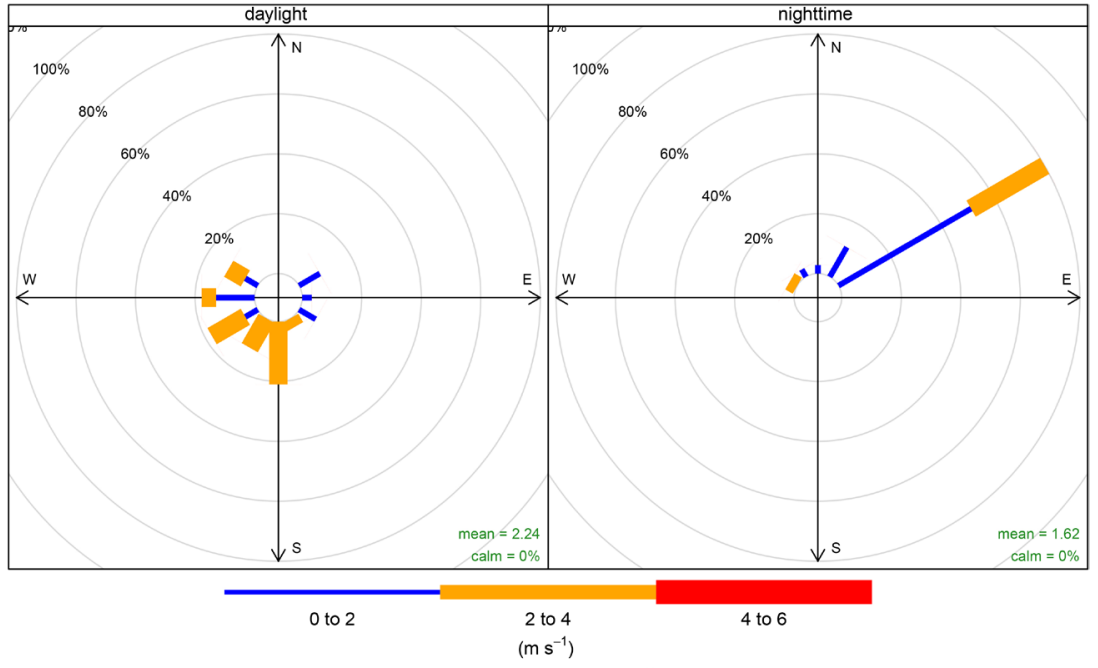

Frequency of counts by wind direction (\%)

(b)

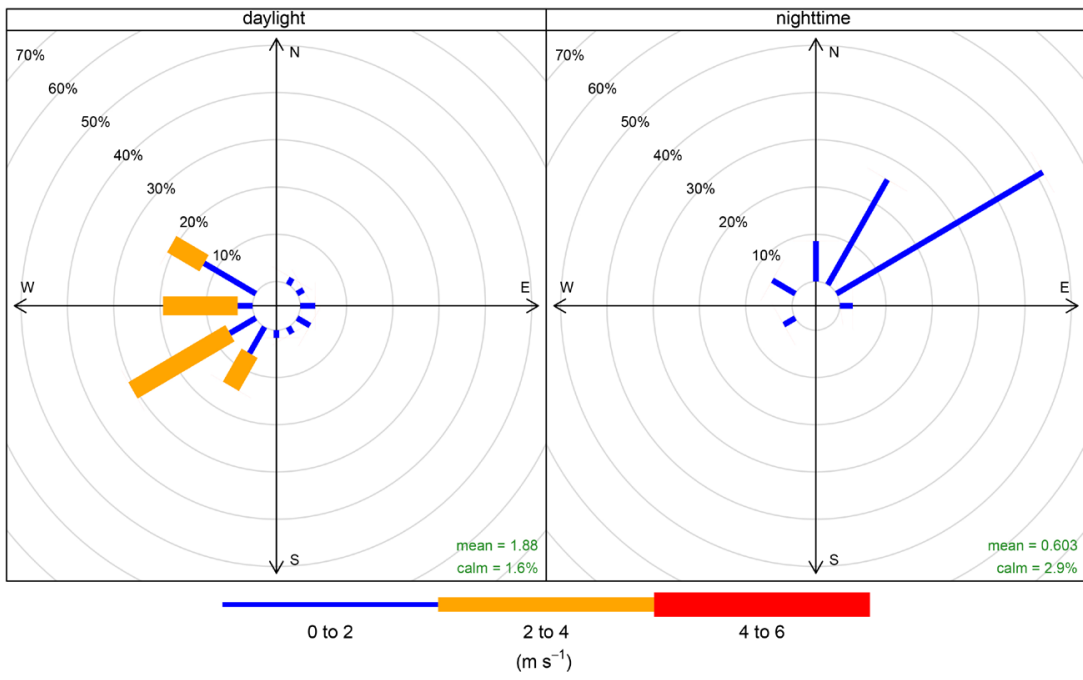

Frequency of counts by wind direction (\%)

(c) 


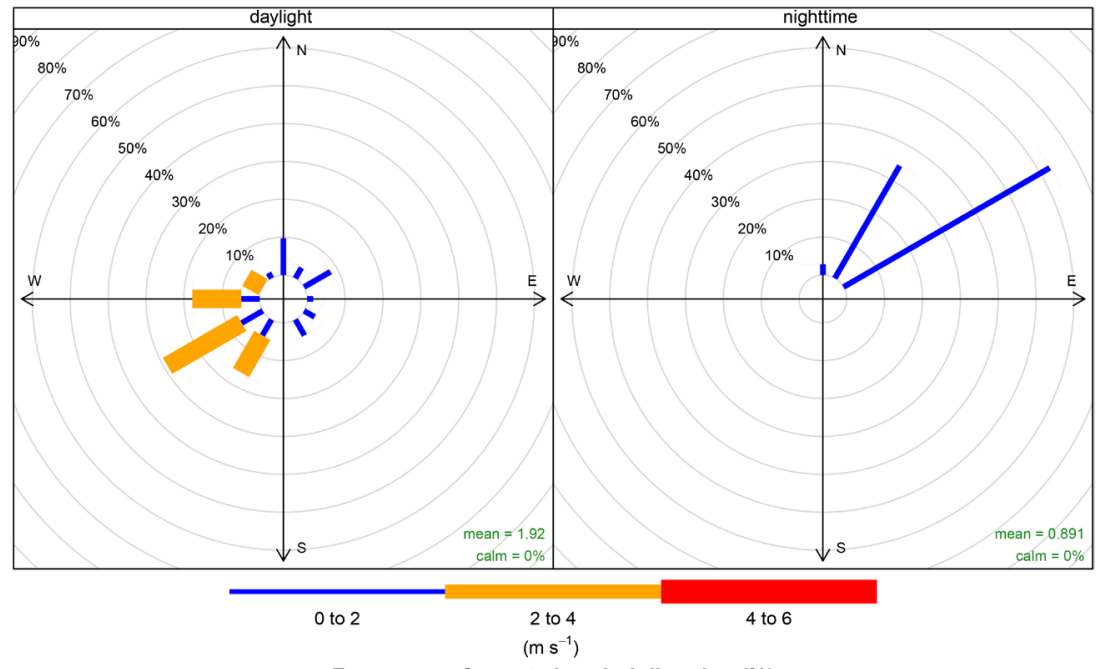

Frequency of counts by wind direction (\%)

(d)

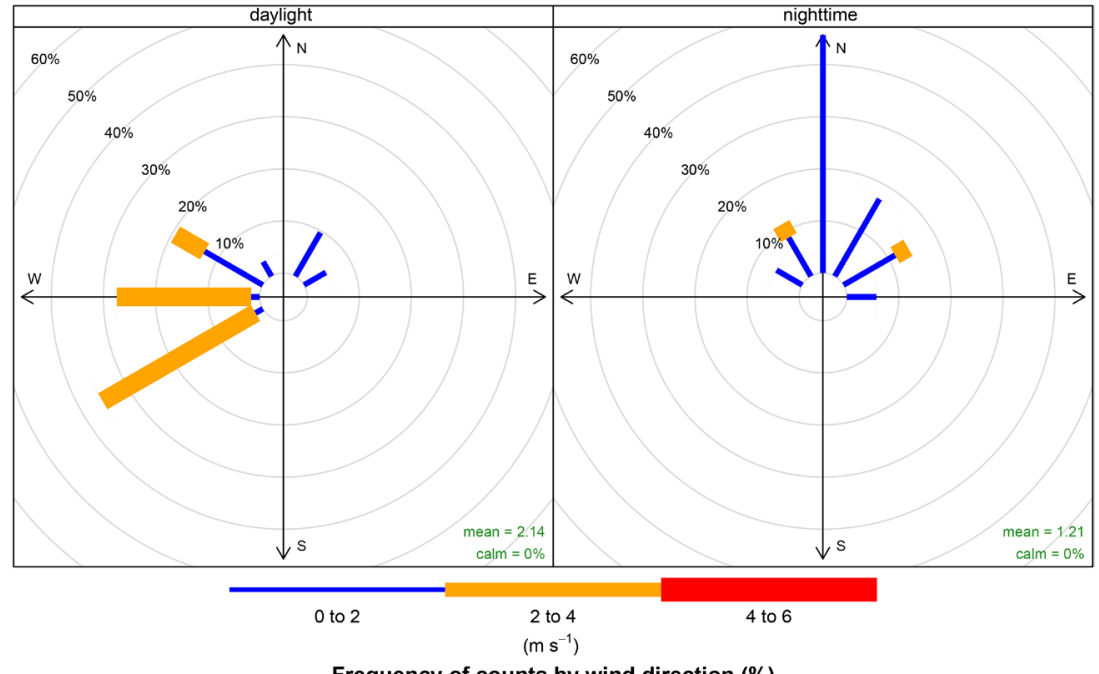

Frequency of counts by wind direction (\%)

(e)

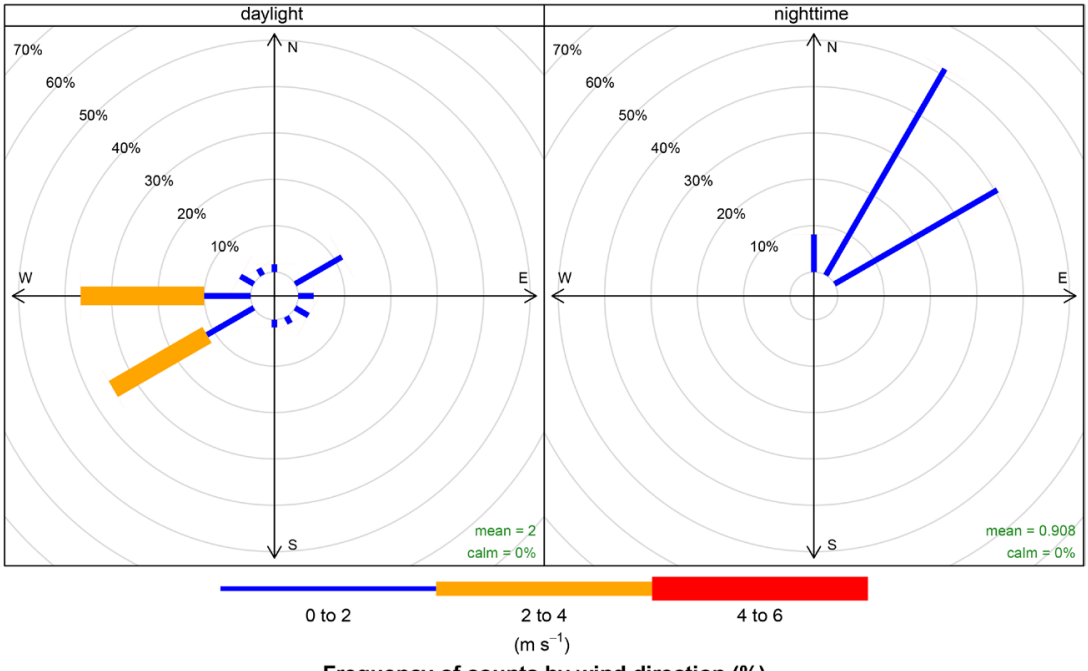

Frequency of counts by wind direction (\%)

(f) 


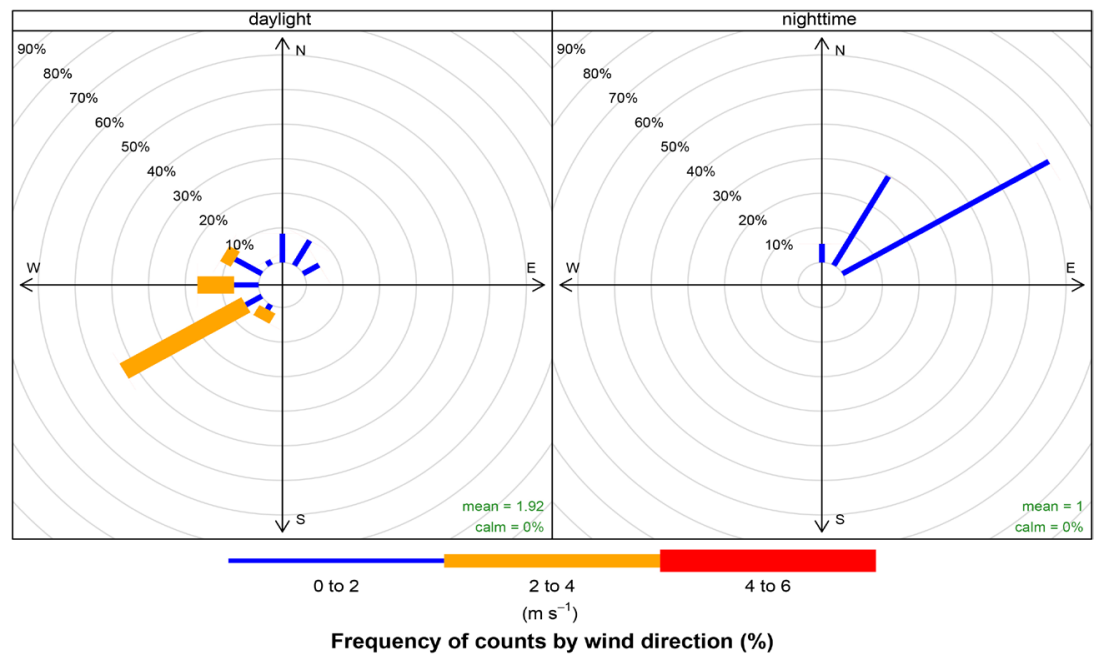

(g)

Figure 3. Wind roses reporting the frequency of counts by wind direction (\%), distinguishing daylight from night-time, for each day of our period of study: (a) 29-Jul; (b) 30-Jul; (c) 31-Jul; (d) 01-Aug; (e) 02-Aug; (f) 03-Aug; (g) 04-Aug, 2016.

the elevation and the amplitude of aerial fires of over 200 meters, together with the almost stable atmospheric conditions during night, can confidently support the belief that our aerosol sampling was able to catch in part the products of the firework gunpowder. It is noteworthy that, as an exception in respect to the other days, during the BKG_0208 a clear prevalent direction from the north was recorded, together with the highest wind speed even detected during nighttime, equal to $1.2 \mathrm{~ms}^{-1}$. This wind condition presumably favored the advection to our sampling site of air masses mostly coming from sea thus influencing the aerosol composition with mostly coarse particles such as sea salt [41].

An in-depth analysis of the wind meteorological data-set can further confirm that around midnight, when approximately the pyrotechnic shows were about to start, the local wind intensity was very low $\left(0.1-0.4 \mathrm{~ms}^{-1}\right)$ while it was growing (up to $1.2 \mathrm{~ms}^{-1}$ ) early in the morning, around 7:00 AM local time. The increase in wind speed was concurrently with the change of wind from eastern to western prevalent direction. The calculated ratio of wind speed (RWS-day/night) was even larger than 1.5, implying that the mean wind speed during daylight was even more intense than that recorded during nighttime (see Figure A2 for more details). Firstly, it could be hypothesized that the stable conditions during nighttime prevented any horizontal diffusion of the aerosols and could, at times, contribute to aerosol stagnation in the local area. Secondly, the stronger wind blowing onshore during daylight otherwise favored both re-suspension and influx of aerosols toward our sampling location.

\subsection{Temporal Evolution}

\subsubsection{Aerosol and Carbon Content}

Over the week of our monitoring study the air quality, in respect with aerosol concentrations, resulted to be quite good at Belvedere M.mo, with $P M_{10}$ and 
$P M_{2.5}$ levels even below $30 \mu \mathrm{g} \cdot \mathrm{m}^{-3}$ and $20 \mu \mathrm{g} \cdot \mathrm{m}^{-3}$, respectively (see Figure 4). The European health thresholds are in fact set equal to $50 \mu \mathrm{g} \cdot \mathrm{m}^{-3}$, as daily limit value for $P M_{10}$, and $25 \mu \mathrm{g} \cdot \mathrm{m}^{-3}$, as annual limit value for $P M_{2.5}$ [42].

Otherwise, during the study period, an interesting inversion in the finer $\left(P M_{2.5}\right)$ and coarser $\left(P M_{2.5-10}\right)$ concentration was observed. By looking Figure 4 it is evident, in terms of both absolute concentration values and $P M_{2.5} / P M_{10}$ ratio, the prevalence of the finer fraction during the three days of the NDF festival, followed by a net decreasing during the next days. The concentrations of $P M_{2.5}$ showed, in fact, a steady increase starting the first day of the Festival (NDF_2907) from a value of $16 \mu \mathrm{g} \cdot \mathrm{m}^{-3}$ with a share of $56 \%$ over the $P M_{10}$ total fraction, reaching the maximum value of $20 \mu \mathrm{g} \cdot \mathrm{m}^{-3}$ and a share of $77 \%$ over the $P M_{10}$ the third Festival day (NDF_3107). During days after the end of the Festival, the $P M_{2.5}$ levels dropped around $10 \mu \mathrm{g} \cdot \mathrm{m}^{-3}$ with a share that was even down to $55 \%$. The only nearest sampling site with air quality data collected in the same period of our study is the Lamezia station. This coastal site faces on the Tyrrhenian Sea and is located at about $80 \mathrm{~km} \mathrm{SSW}$ in respect to Belvedere M.mo [37]. During the same sampling period of our observations at Belvedere, the values recorded at Lamezia station for $P M_{2.5}$ were even lower than $10 \mu \mathrm{g} \cdot \mathrm{m}^{-3}$ [43]. As it can be seen in Figure 4, we recorded $P M_{2.5}$ around this same value of $10 \mu \mathrm{g} \cdot \mathrm{m}^{-3}$ during our background conditions. During the Festival the finer particles reached instead a higher level, ranging from 16 to $20 \mu \mathrm{g} \cdot \mathrm{m}^{-3}$. This comparison highlights the potential influence of the festival on air quality at Belvedere. The

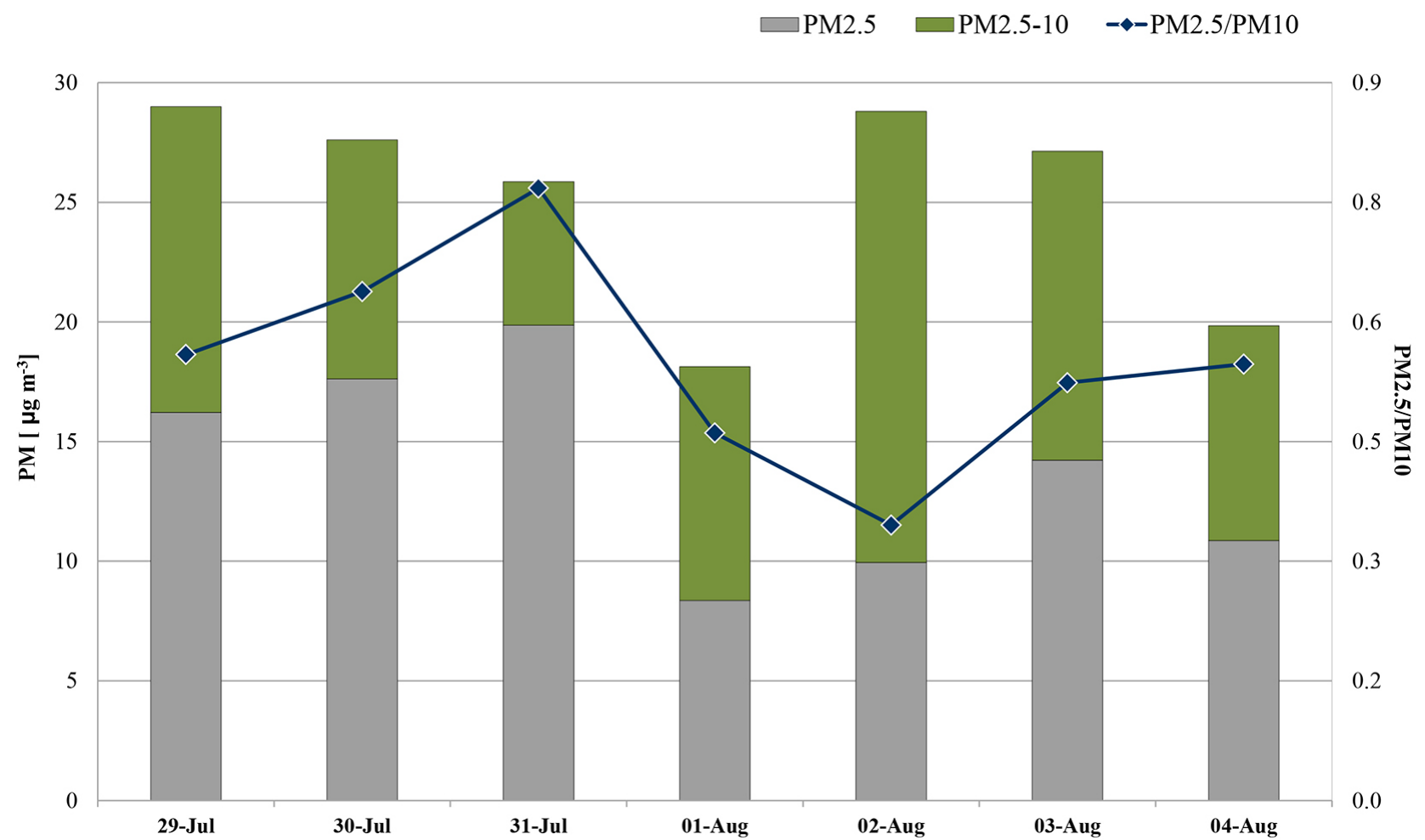

Figure 4. Evolution of concentrations of Fine $\left(P M_{2.5}\right.$-grey) and Coarse $\left(P M_{2.5-10}\right.$-green) particles and their ratio over the week of study. 
minimum $P M_{2.5}$ contribution, with a value of $35 \%$, was recorded the day with no events (BKG_0208), during which a concomitant raising of the coarser particles, up to $19 \mu \mathrm{g} \cdot \mathrm{m}^{-3}$, was detected. As an exception over the entire period, a slight increase in $P M_{2.5}$ levels, around $15 \mu \mathrm{g} \cdot \mathrm{m}^{-3}$, was recorded at our sampling location the day identified as MKT_0308, probably influenced by the greater flow of cars and trucks usually occurring each Wednesday at Belvedere M.mo town during the Market's activity.

For both, directly recorded, $P M$ size fractions $\left(P M_{10}\right.$ and $\left.P M_{2.5}\right)$ Table 2 reports a summary regarding their total mass concentrations along with the values obtained for the carbonaceous species, TC $(\mathrm{EC}+\mathrm{OC})$, the results for their relative contribution, their ratios, and also calculations for the Secondary Organic Carbon (SOC) component. Our analysis showed a higher, even if slight, prevalence of TC levels for all the three days of the festival, during which the TC value was up to $4 \mu \mathrm{g} \cdot \mathrm{m}^{-3}$, reaching the maximum recorded value the third day of NDF with a level of TC equal to $4.68 \mu \mathrm{g} \cdot \mathrm{m}^{-3}$. Once the Festival finished, the carbon content decreased reaching the minimum value $3.26 \mu \mathrm{g} \cdot \mathrm{m}^{-3}$ the day BKG_0208.

In general, the relationship between the OC and EC atmospheric concentrations gives qualitative information regarding the sources contributing to carbonaceous species in PM [44]. If OC and EC are released into the atmosphere by common primary sources, the two carbonaceous species should be well-correlated [45]. The weaker correlation found in $P M_{2.5}$ and $P M_{10}\left(R^{2}=0.56\right.$,

Table 2. Mass concentration ( $P M)$, Total Carbon (TC), Organic Carbon (OC), Elemental Carbon (EC) along with calculations for the carbonaceous species, are reported for both $P M_{2.5}$ and $P M_{10}$ size fractions for each day of our sampling period.

\begin{tabular}{|c|c|c|c|c|c|c|c|c|c|c|c|}
\hline & Sample ID & $P M$ & $\mathrm{TC}$ & OC & EC & $\mathrm{TC} / P M$ & $\mathrm{OC} / P M$ & $\mathrm{EC} / P M$ & $\mathrm{OC} / \mathrm{EC}$ & SOC & SOC/OC \\
\hline & & $\mu \mathrm{g} \cdot \mathrm{m}^{-3}$ & $\mu \mathrm{g} \cdot \mathrm{m}^{-3}$ & $\mu \mathrm{g} \cdot \mathrm{m}^{-3}$ & $\mu \mathrm{g} \cdot \mathrm{m}^{-3}$ & $\%$ & $\%$ & $\%$ & & $\mu \mathrm{g} \cdot \mathrm{m}^{-3}$ & $\%$ \\
\hline \multirow{6}{*}{$7^{\star} P M_{2.5}$} & NDF_2907 & 17.62 & 4.13 & 3.68 & 0.45 & $23.5 \%$ & $20.9 \%$ & $2.5 \%$ & 8.23 & 0.46 & $12 \%$ \\
\hline & NDF_3107 & 19.86 & 4.03 & 3.68 & 0.35 & $20.3 \%$ & $18.5 \%$ & $1.8 \%$ & 10.59 & 1.18 & $32 \%$ \\
\hline & BKG_0108 & 8.36 & 3.44 & 3.16 & 0.28 & $41.1 \%$ & $37.8 \%$ & $3.3 \%$ & 11.50 & 1.18 & $37 \%$ \\
\hline & BKG_0208 & 9.95 & 2.97 & 2.71 & 0.26 & $29.8 \%$ & $27.2 \%$ & $2.6 \%$ & 10.46 & 0.84 & $31 \%$ \\
\hline & MKT_0308 & 14.22 & 3.29 & 3.03 & 0.27 & $23.2 \%$ & $21.3 \%$ & $1.9 \%$ & 11.38 & 1.11 & $37 \%$ \\
\hline & BKG_0408 & 10.86 & 3.00 & 2.64 & 0.37 & $27.6 \%$ & $24.3 \%$ & $3.4 \%$ & 7.20 & 0.00 & $0 \%$ \\
\hline \multirow{6}{*}{$7^{\star} P M_{10}$} & NDF_2907 & 27.61 & 4.34 & 3.74 & 0.60 & $15.7 \%$ & $13.6 \%$ & $2.2 \%$ & 6.28 & 0.10 & $3 \%$ \\
\hline & NDF_3107 & 25.87 & 4.68 & 4.20 & 0.48 & $18.1 \%$ & $16.2 \%$ & $1.9 \%$ & 8.73 & 1.26 & $30 \%$ \\
\hline & BKG_0108 & 18.14 & 3.86 & 3.43 & 0.43 & $21.3 \%$ & $18.9 \%$ & $2.4 \%$ & 8.00 & 0.81 & $24 \%$ \\
\hline & BKG_0208 & 28.75 & 3.26 & 2.80 & 0.46 & $11.4 \%$ & $9.8 \%$ & $1.6 \%$ & 6.11 & 0.00 & $0 \%$ \\
\hline & MKT_0308 & 27.14 & 3.60 & 3.12 & 0.48 & $13.3 \%$ & $11.5 \%$ & $1.8 \%$ & 6.45 & 0.17 & $5 \%$ \\
\hline & BKG_0408 & 19.85 & 3.81 & 3.35 & 0.46 & $19.2 \%$ & $16.9 \%$ & $2.3 \%$ & 7.21 & 0.51 & $15 \%$ \\
\hline
\end{tabular}


$\left.R^{2}=0.28\right)$ observed in our dataset indicated that the sources of OC at our sampling site were different from those of EC and/or can be the result of the presence of different emission sources, having significantly different OC/EC ratios.

At the same time, the OC/EC ratio is strongly source dependent, and provides a valuable tool to obtain information on the emission sources and the transformations of carbonaceous aerosol, identifying the secondary organic aerosol (SOA) formation. In fact, organic aerosol can be emitted directly into the atmosphere as primary particles or it can be of secondary origin. When volatile organic compounds (VOC) are oxidized in the atmosphere, they produce oxidized volatile organic compounds (OVOC) which condense onto pre-existing aerosol forming secondary organic aerosol (SOA). As Table 2 shows, the SOC estimated for our study using the EC tracer method and the minimum OC/EC ratio, was found to be an appreciable component of particle mass with contribution to OC ranging between 3 and $30 \%$ in the $P M_{10}$ fraction, with relatively higher values in $P M_{2.5}(12 \%-37 \%)$.

In our study case, the OC/EC ratio showed a considerable variation of values around 10 and 7 , for $P M_{2.5}$ and $P M_{10}$, respectively. These relatively high values suggest a clear prevalence of the OC contribution over EC, which could be attributed to significant local sources with higher OC and lower EC emission rates. During the Festival, meat and pizza cooking systems were widely used on the promenade close to the Capo Tirone sea basin. These cooking methods are all based on the combustion of biomass burning, an important OC source which leads to the increase of the amount of carbonaceous particles of primary origin. Thus, due to our observations, it could be hypothesize an important contribution of this kind of source over the organic carbon content of particles collected at our sampling location.

It is also interesting to observe the distribution of EC and OC between the fine and coarse particle size fractions. In fact, even if lower values, for both EC and OC levels, were measured for days after the Festival, it is possible to notice an increasing OC/EC ratio in the finer fractions (see Table 2). This occurrence could be explained by the fact that low wind speed observed during the study could help in trapping pollution gases near the surface followed by their secondary transformation and subsequent condensation onto pre-existing aerosols. As a result, concentrations of secondary components may be high, mainly in finer fraction, and in the post-firework period as confirmed by our calculation for the contribution of SOC to the corresponding OC values, and as also observed elsewhere by [9] and by [23].

\subsubsection{Major and Trace Elements}

Over the whole study period, 7 Major ( $\mathrm{Na}, \mathrm{Al}, \mathrm{K}, \mathrm{Fe}, \mathrm{Ca}, \mathrm{Mg}, \mathrm{Ti})$ and $7 \mathrm{Trace}(\mathrm{V}$, $\mathrm{Cu}, \mathrm{Ba}, \mathrm{Pb}, \mathrm{Mn}, \mathrm{Sr}, \mathrm{Ni}$ ) Elements were detected. For each of the above mentioned elements Table 3 reports mean, Standard Deviation (SD), minimum (min) and Maximum (Max) values. Elements are ordered following descending mean values obtained for both $P M_{2.5}$ and $P M_{2.5-10}$ particle size fractions. 
Table 3. Mean, Standard Deviation (SD), minimum (min), and Maximum (Max) values are reported for Major and Trace elements detected during the study period on both Fine $\left(P M_{2.5}\right)$ and Coarse $\left(P M_{2.5-10}\right)$ particle size fractions. Maximum values are highlighted in bold in case they have been recorded during a Festival day.

\begin{tabular}{|c|c|c|c|c|c|c|c|c|c|c|}
\hline & \multicolumn{5}{|c|}{$P M_{2.5}$} & \multicolumn{5}{|c|}{$P M_{2.5-10}$} \\
\hline & & Mean & SD & $\min$ & $\operatorname{Max}$ & & Mean & SD & $\min$ & $\operatorname{Max}$ \\
\hline \multirow{8}{*}{$\begin{array}{l}7^{\star} \text { Major } \\
\text { Elements } \\
{\left[\mathrm{ng} \cdot \mathrm{m}^{-3}\right]}\end{array}$} & & & & & & & & & & \\
\hline & $\mathrm{Na}$ & 267 & 166 & 101 & 590 & $\mathrm{Na}$ & 650 & 369 & 399 & 1470 \\
\hline & $\mathrm{Al}$ & 14 & 98 & 78.7 & 316 & $\mathrm{Ca}$ & 162 & 76.6 & 5.0 & 232 \\
\hline & $\mathrm{K}$ & 99.4 & 54.2 & 33.4 & 175 & $\mathrm{Al}$ & 160 & 103 & 3.0 & 279 \\
\hline & $\mathrm{Fe}$ & 69.1 & 38.8 & 27.7 & 141 & $\mathrm{Fe}$ & 154 & 48.5 & 54.6 & 198 \\
\hline & $\mathrm{Ca}$ & 68.7 & 35.9 & 40.0 & 111 & $\mathrm{Mg}$ & 134 & 42.1 & 87.0 & 222 \\
\hline & $\mathrm{Mg}$ & 48.8 & 28.0 & 16.0 & 89.3 & $\mathrm{~K}$ & 70.9 & 40.0 & 2.0 & 123 \\
\hline & $\mathrm{Ti}$ & 11.2 & 9.1 & 6.3 & 28.9 & $\mathrm{Ti}$ & 12.4 & 7.5 & 3.4 & 21.8 \\
\hline $\begin{array}{c}\text { \%MEs } \\
\text { over } P M\end{array}$ & & $5 \%$ & $3 \%$ & $2 \%$ & $12 \%$ & & $13 \%$ & $5 \%$ & $5 \%$ & $19 \%$ \\
\hline $7^{\star}$ Trace & & & & & & & & & & \\
\hline \multirow{7}{*}{$\begin{array}{c}\text { Elements } \\
{\left[\mathrm{ng} \cdot \mathrm{m}^{-3}\right]}\end{array}$} & $\mathrm{V}$ & 3.1 & 0.9 & 2.1 & 4.5 & $\mathrm{Cu}$ & 5.7 & 2.4 & 0.9 & 7.9 \\
\hline & $\mathrm{Cu}$ & 2.8 & 0.6 & 1.9 & 3.5 & $\mathrm{Ba}$ & 4.6 & 4.4 & 0.2 & 10.5 \\
\hline & $\mathrm{Ba}$ & 2.6 & 1.2 & 1.7 & 4.2 & $\mathrm{Mn}$ & 2.5 & 1.0 & 0.9 & 3.9 \\
\hline & $\mathrm{Pb}$ & 1.5 & 0.5 & 0.7 & 1.9 & $\mathrm{Sr}$ & 1.6 & 0.8 & 0.1 & 2.3 \\
\hline & $\mathrm{Mn}$ & 1.4 & 1.0 & 0.3 & 2.7 & $\mathrm{~V}$ & 0.8 & 0.6 & 0.2 & 1.6 \\
\hline & $\mathrm{Sr}$ & 1.0 & 0.5 & 0.6 & 1.8 & $\mathrm{~Pb}$ & 0.4 & 0.4 & 0.1 & 1.1 \\
\hline & $\mathrm{Ni}$ & 1.0 & 0.3 & 0.7 & 1.3 & $\mathrm{Ni}$ & 0.2 & 0.1 & 0.1 & 0.3 \\
\hline $\begin{array}{c}\text { \%TEs over } \\
P M\end{array}$ & & $0.08 \%$ & $0.02 \%$ & $0.04 \%$ & $0.11 \%$ & & $0.13 \%$ & $0.08 \%$ & $0.01 \%$ & $0.24 \%$ \\
\hline
\end{tabular}

Maximum values are further highlighted in bold in case that they have been recorded during a Festival day.

Elements with mean concentration up to $10 \mathrm{ng} \cdot \mathrm{m}^{-3}$ in $P M_{2.5}$ or in $P M_{2.5-10}$ were identified as Major Elements (MEs). In our samples, levels varying from a minimum mean value of $11.2 \pm 9.1$ and $12.4 \pm 7.5$ for Ti until values of $2667 \pm 166$ and $650 \pm 369 \mathrm{ng} \cdot \mathrm{m}^{-3}$ for $\mathrm{Na}$, were observed in $P M_{2.5}$ and $P M_{2.5-10}$, respectively (see Table 3). Mean concentration of the detected MEs was observed to be in the order of $\mathrm{Na}>\mathrm{Al}>\mathrm{K}>\mathrm{Fe}>\mathrm{Ca}>\mathrm{Mg}>\mathrm{Ti}$ in the finest fraction while it was $\mathrm{Na}>$ $\mathrm{Ca}>\mathrm{Al}>\mathrm{Fe}>\mathrm{Mg}>\mathrm{K}>\mathrm{Ti}$ in the coarser one, thus revealing a prevailing concentration of $\mathrm{K}$ in $P M_{2.5}$, which was even larger during the three days of the NDF Festival. The total amount of MEs accounted for $2 \%-12 \%$ and $5 \%-19 \%$ of the total $P M_{2.5}$ and $P M_{2.5-10}$ mass concentrations, respectively. As it can be noted by numbers in bold in Table 3, in both $P M_{2.5}$ and $P M_{2.5-10}$, all MEs reached the maximum value in correspondence of the NDF Festival, except for $\mathrm{Na}$ and $\mathrm{Mg}$ that otherwise peaked during the background day identified as BKG_0208. Dur- 
ing this day the wind was more intense in the direction NNW (from the sea) thus favouring a substantial injection of sea spray, of which $\mathrm{Na}$ is a tracer, as well as of sandy dust, whose a maker is $\mathrm{Mg}$ [41]. Contrarily from the finer fraction, the maximum value of $\mathrm{K}$ in the coarser fraction was recorded the day BKG_0108. The different behavior of $\mathrm{K}$ in the two particle fractions implies they originated from two sources, in particular, larger $\mathrm{K}$ levels in $P M_{2.5}$ during the Festival can be confidently attributed to fireworks being the $\mathrm{K}$ itself recognized as a good tracers of the emissions from fireworks [9].

Elements with mean concentration lower than $10 \mathrm{ng} \cdot \mathrm{m}^{-3}$ but higher than 1 ng. $\mathrm{m}^{-3}$ in $P M_{2.5}$ and/or in $P M_{2.5-10}$ were identified as Trace Elements (TEs). Their amount in our study case varied from $0.04 \%$ to $0.1 \%$ in $P M_{2.5}$ and from $0.01 \%$ to $0.24 \%$ in $P M_{2.5-10}$. In the finer fraction, the higher mean concentration was observed for $\mathrm{V}\left(3.1 \pm 0.9 \mathrm{ng} \cdot \mathrm{m}^{-3}\right)$ and followed by $\mathrm{Cu}\left(2.8 \pm 0.6 \mathrm{ng} \cdot \mathrm{m}^{-3}\right)$. In the coarser fraction, the larger mean value was otherwise detected for $\mathrm{Cu}(5.7 \pm 2.4$ $\left.\mathrm{ng} \cdot \mathrm{m}^{-3}\right)$ and followed by $\mathrm{Ba}\left(4.6 \pm 4.4 \mathrm{ng} \cdot \mathrm{m}^{-3}\right)$. By looking at Table 3 the different order of TE concentrations in $P M_{2.5}$ and $P M_{2.5-10}$, it is possible to notice the larger enrichment of $\mathrm{V}$ (range of value: $2.1-4.5 \mathrm{ng} \cdot \mathrm{m}^{-3}$ ) and $\mathrm{Pb}(0.7-1.9$ $\mathrm{ng} \cdot \mathrm{m}^{-3}$ ) in the finer fraction in respect with that recorded in the coarser one where values varied from 0.2 to $1.6 \mathrm{ng} \cdot \mathrm{m}^{-3}$ and from 0.1 to $1.1 \mathrm{ng} \cdot \mathrm{m}^{-3}$ for $\mathrm{V}$ and $\mathrm{Pb}$, respectively. Regarding $\mathrm{Pb}$, levels were found to be below the annual limit value set by EU legislation and set to $0.5 \mu \mathrm{g} \cdot \mathrm{m}^{-3}$. Similarly for $\mathrm{Ni}$, whose target yearly value is equal to $20 \mathrm{ng} \cdot \mathrm{m}^{-3}$ while in our samples it was found to be lower than 1.3 and $0.3 \mathrm{ng} \cdot \mathrm{m}^{-3}$ in $P M_{2.5}$ and $P M_{2.5-10}$, respectively (see Table 3). It is important to note that in the finer particle mode, with the only exception of $\mathrm{Ni}$, each TE reached the maximum value in correspondence of a day within the NDF festival. The behavior of TEs was different in the coarser particle mode: only Ba and Mn peaked during NDF while the other ones recorded maximum values during a BKG day.

\subsection{Events Influence}

\subsubsection{Aerosol and Carbon Content}

Levels of aerosol mass, carbon content and elemental concentration, already presented as temporal evolution over the study period in the previous paragraphs, were further grouped according to the various occurring events (NDF, $\mathrm{MKT}$ and $\mathrm{BKG}$ ), and discussed in terms of their inter-variability.

As Table 4 shows, the $P M_{2.5}$ mean level $\left(17.9 \pm 1.8 \mu \mathrm{g} \cdot \mathrm{m}^{-3}\right)$, obtained as average of the daily $P M_{2.5}$ concentrations recorded during the 3 days of the NDF Festival, was almost double in respect to that revealed at the Background conditions $\left(9.7 \pm 1.3 \mu \mathrm{g} \cdot \mathrm{m}^{-3}\right)$. The value obtained during the Market event was intermediate between the last two ones. Particulate EC and OC in the finer mode both showed higher mean values in correspondence of the NDF event, followed by those recorded the day with Market. Differently, for the coarser fraction it seems that there was not a contributing source during the Festival. 
Table 4. Mean and Standard Deviation (SD) for total mass concentration ( $P M)$ along with EC and OC content obtained over each single event period (Note di Fuoco, Market and Background), and associated with both Fine $\left(P M_{2.5}\right)$ and Coarse $\left(P M_{2.5-10}\right)$ particle size fractions.

\begin{tabular}{ccccccccccc}
\hline & \multicolumn{9}{c}{$\boldsymbol{P M}_{2.5}$} & \multicolumn{9}{c}{$\boldsymbol{P M}_{2.5-10}$} \\
\cline { 2 - 11 } & Note di Fuoco & Market & Background & Note di Fuoco & Market & Background \\
\cline { 2 - 10 }$(\mathrm{n}=3)$ & $(\mathrm{n}=1)$ & $(\mathrm{n}=3)$ & $(\mathrm{n}=3)$ & $(\mathrm{n}=1)$ & $(\mathrm{n}=3)$ \\
\hline $\begin{array}{c}\text { Conc } \\
{\left[\mu \mathrm{g} \cdot \mathrm{m}^{-3}\right]}\end{array}$ & Mean & SD & Mean & Mean & SD & Mean & SD & Mean & Mean & SD \\
\hline$P M$ & 17.9 & 1.8 & 14.2 & 9.7 & 1.3 & 9.6 & 3.4 & 12.9 & 12.5 & 5.4 \\
EC & 0.4 & 0.1 & 0.3 & 0.3 & 0.1 & 0.1 & 0.0 & 0.2 & 0.2 & 0.1 \\
OC & 3.7 & 0.0 & 3.0 & 2.8 & 0.3 & 0.3 & 0.2 & 0.1 & 0.4 & 0.3 \\
\hline
\end{tabular}

The percentage variation of aerosol particle levels measured during the Festival itself in respect with those recorded at Background conditions shows a negative variation, around $20 \%$, for $P M_{2.5-10}$ mass concentration as well as for its EC and OC content, while for $P M_{2.5}$ there was an increment up of $80 \%$ for the total mass concentration that was instead about 30\% for both EC and OC (see Figure A3 for more details).

\subsubsection{Major and Trace Elements}

To better evaluate the influence of the NDF Festival on the elemental particle concentrations, the percentage variation between levels recorded during NDF and BKG days was calculated, highlighting the different behavior of finer and coarser particles (see Figure A4 for more details).

For $P M_{2.5}$-associated elements with the only exception of $\mathrm{Na}$ and $\mathrm{Ni}$ there was a positive contribution of NDF with an increase up to $50 \%$ for $\mathrm{Fe}, \mathrm{Ti}, \mathrm{K}$ within Major and for $\mathrm{Mn}, \mathrm{Pb}, \mathrm{Sr}$ in Trace Elements. Although $\mathrm{Fe}$ is not an element typically originated from fireworks, it showed a significant increase during the NDF period. Fe is in fact used to make gold sparks; its oxides are usually used as high-temperature oxidizers in fireworks while $\mathrm{Ti}$ is used to provide silvery effects [7].

As known, potassium salts might be one of the major compounds used in fireworks and potassium could serve as a tracer of the emissions from fireworks [9]. Interestingly, in our study $\mathrm{K}$ in the fine fraction showed strong correlation with $\mathrm{Pb}$, and $\mathrm{Sr}\left(R^{2}=0.86\right.$ in both cases), indicating they are largely from fireworks. In fact, $\mathrm{Pb}$ could help to achieve a steady and reproducible burning rate as well as to produce crackling micro-stars [3]. Otherwise Sr, in the form of strontium nitrate and strontium sulfate, is employed to give the red color to flares, fires, and stars; besides, $\mathrm{Sr}$ atoms also serve as a stabilizer for the mixtures. In contrast to the other trace elements, concentrations of $\mathrm{Ni}$ dropped during the Festival. This metal is considered tracer of vehicular (fuel combustion) source. Traffic during NDF was interdicted for security, being thus the probable explanation of the lower values observed for $\mathrm{Ni}$ itself during the Festival. 
For $P M_{2.5-10}$-associated elements, an important increase $(\Delta>40 \%)$ was recorded only for $\mathrm{Ba}$ and $\mathrm{Al}$ while the others elements showed minor positive variation or even a negative contribution. These results could be explained by the fact that fireworks burning produce mainly finer particles that have much shorter residence times in the atmosphere and will convert through aggregation or coagulation to coarser particles whose levels increased the days before the Festival.

To distinguish the fireworks-induced changes in the elemental compositions of the fine particles from the coarse particles, the $P M_{2.5}$-to- $P M_{10}$ ratios (concentration of element associated with $P M_{2.5} /$ concentration of element associated with $P M_{10}$ ) for each of the elements identified in this study was further determined. As indicated in Figure 5 the $P M_{2.5} / P M_{10}$ ratio was higher during the NDF period with respect to the BKG one for all the Major and Trace elements with the only exception of $\mathrm{Ba}$ and $\mathrm{Ni}$. This behavior can be explained by considering that the burning of fireworks increased the level of fine aerosol particles, which remained suspended in the air before they coagulated into coarser particles that dropped on the ground. The higher ratio found in this study for $\mathrm{K}, \mathrm{Pb}$ and $\mathrm{V}$ well agrees with that reported by [3].

Although there have been only a limited number of other studies on atmospheric emissions emanating from fireworks, it is clear that such particle emissions have their distinctive physio-chemical composition. The firework tracer elements did not show an increment in the coarser mode neither in the study carried out in Milan and reported by [10], thus confirming that ambient aerosol during fireworks event is preferably confined in the fine fraction.

\section{Conclusions}

In this study, $P M_{2.5}$ and $P M_{10}$ aerosols were recorded in summer 2016 during the Note di Fuoco Festival to evaluate the general impact induced from the overall Festival itself on the ambient air quality at Belvedere M.mo, a rural area facing on the Tyrrhenian coast of Italy. Elemental and Organic Carbon along with 14 major and trace elements has been measured by the thermo-optical method and ICP-MS, respectively. This paper is designed as a contribution towards understanding the distinctive and unusual chemistry of the anthropogenic aerosol burden created by firework displays together with related influencing sources. The outcomes from this study confirmed that particles induced during the overall period featured by pyrotechnic shows were characterized by a high $P M_{2.5} / P M_{10}$ ratio and contain a complex mixture of different trace metals. Our measurements specifically showed that $P M_{2.5}$ was double during the NDF Festival compared to background conditions. In particular, the analytical results revealed that the concentrations of many of the major and trace elements contributed mainly to the finer, more toxic and inhalable particulate size fraction. Some elements that play an indispensable role in forming the various colours seen during the burning of fireworks, namely $\mathrm{K}, \mathrm{Cu}, \mathrm{Sr}$, and $\mathrm{Ba}$, were found in higher concentrations. The most notable increases in our study involved $\mathrm{Ba}, \mathrm{Sr}$, $\mathrm{Pb}$, and $\mathrm{Sb}, \mathrm{Mg}, \mathrm{Ti}$ showing lesser increases. In this preliminary 


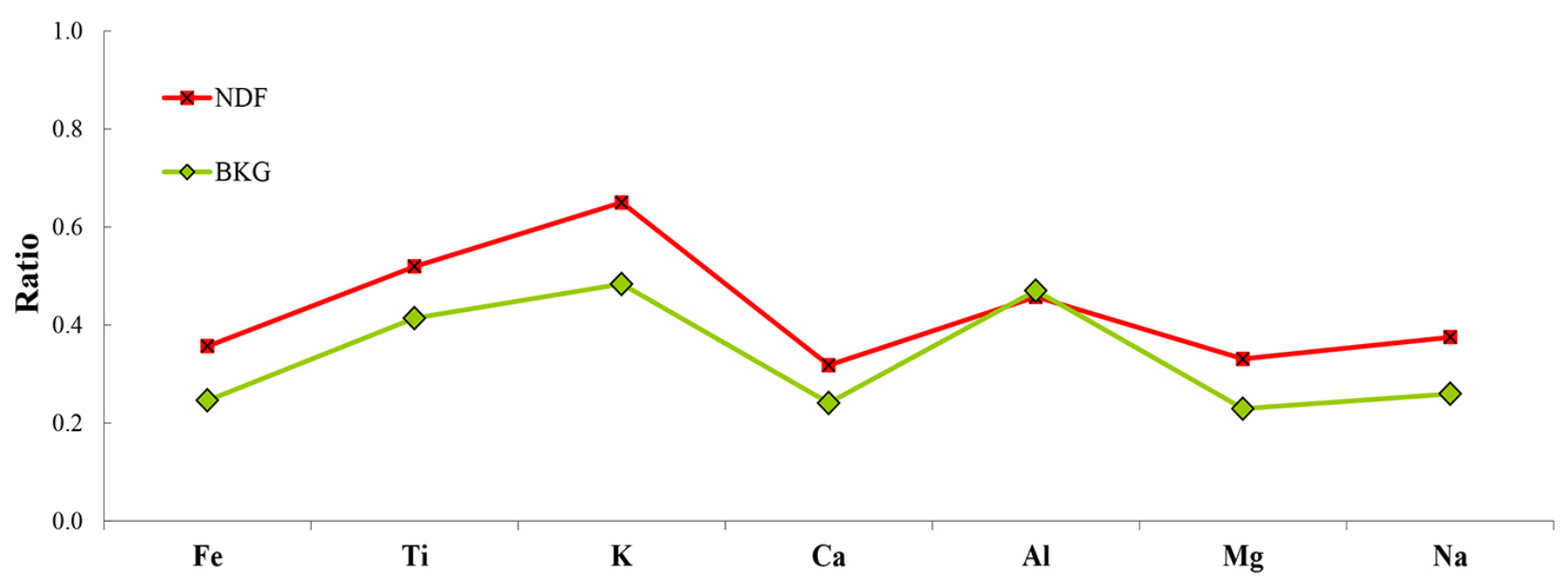

(a)

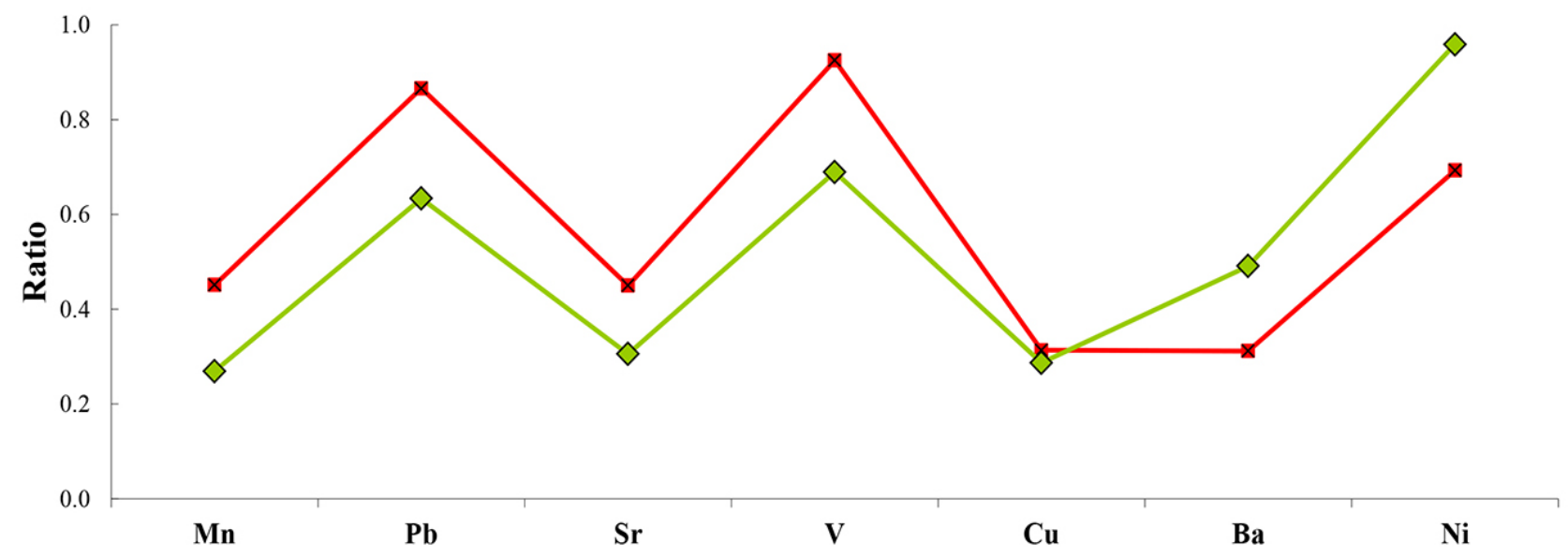

(b)

Figure 5. Ratio between $P M_{2.5}$ to $P M_{2.5-10}$ corresponding levels for Major and Trace elements.

investigation, we also were able to recognize the likely influence of the cooking street systems which, based on biomass burning, mainly resulted in an increase in organic carbonaceous component of the recorded particles.

As an added value, in a forthcoming study, it will be necessary to sample aerosols variation with a major temporal resolution to be able to check variations in chemicals and distribution of aerosols when the prevailing wind starts deviating from onshore to offshore, due to land and sea breeze which characterizes our sampling location. In such a way, it would also possible to verify the real impact of the firework displays and distinguish it from other contributing sources induced by the Festival itself. In addition to the aerosol physical-chemical composition, it would be useful to monitor also the main primary and secondary gas pollutants such as $\mathrm{NO}_{x}, \mathrm{SO}_{2}$ and $\mathrm{O}_{3}$. Taking this into account, it will allow to better understand and characterize mechanisms and processes involved in the increase of pollution load in a rural location, like Belvedere M.mo, that generally recall a huge number of tourists during such kind of summer events.

With these preliminary results in mind, we can affirm that although fire- 
work-related recreational pollution episodes are transient in nature, they are generally highly concentrated, and are on average fine enough to be easily inhaled and have a health risk for susceptible individuals. On the other hand, as Clark (1997) has noted, regulating or banning such events would be socially unacceptable; however, adequate knowledge of the scenario is vital to ensure that the sensitive population takes precautionary measures.

\section{Acknowledgements}

The authors would like to thank the municipal administration of Belvedere M.mo. Many thanks also to the Multi-hazard Functional Center of the Regional Agency for Environmental Protection of Calabria (Arpacal), for providing meteorological data from the weather station in Belvedere M.mo. A special thanks for their support and encouragement of this work to Valeria Bruni, Francesca Straface, Nadia Mancuso, Angela Martire, Ugo Lanzafame, Lindo Nudo, Yonereidy Bejerano, Gianbattista Ranieri, Giovanni Amendola, Roberto Giacomantonio, Fabrizio Lo Scudo, Barbara Aurea and Giuseppe Tortora. Finally, the authors are grateful to Salvatore Bencardino and Marisa Serafini for their technical assistance and valuable support.

\section{References}

[1] Drewnick, F., Hings, S.S., Curtius, J., Eerdekens, G. and Williams, J. (2006) Measurement of Fine Particulate and Gas-Phase Species during the New Year's Fireworks 2005 in Mainz, Germany. Atmospheric Environment, 40, 4316-4327. https://doi.org/10.1016/j.atmosenv.2006.03.040

[2] Wehner, B., Wiedensohler, A. and Heintzenberg, J. (2000) Submicrometer Aerosol Size Distributions and Mass Concentration of the Millennium Reworks 2000 in Leipzig, Germany. Journal of Aerosol Science, 31, 1489-1493.

[3] Do, T.M., Wang, C.F., Hsieh, Y.K. and Hsieh, H.F. (2012) Metals Present in Ambient Air before and after a Rework Festival in Yanshui, Tainan, Taiwan. Aerosol and Air Quality Research, 12, 981-993.

[4] Barman, S., Singh, R., Negi, M. and Bhargava, S. (2008) Ambient Air Quality of Lucknow City (India) during Use of Fireworks on Diwali Festival. Environmental Monitoring and Assessment, 137, 495-504. https://doi.org/10.1007/s10661-007-9784-1

[5] Tiwari, S., Chate, D., Srivastava, M., Safai, P., Srivastava, A., Bisht, D. and Padmanabhamurty, B. (2012) Statistical Evaluation of $\mathrm{PM}_{10}$ and Distribution of $\mathrm{PM}_{1}$, $\mathrm{PM}_{2.5}$, and $\mathrm{PM}_{10}$ in Ambient Air Due to Extreme Fireworks Episodes (Deepawali Festivals) in Megacity Delhi. Natural Hazards, 61, 521-531.

https://doi.org/10.1007/s11069-011-9931-4

[6] Ambade, B. and Ghosh, S. (2013) Characterization of $\mathrm{PM}_{10}$ in the Ambient Air during Deepawali Festival of Rajnandgaon District, India. Natural Hazards, 69, 589-598. https://doi.org/10.1007/s11069-013-0725-8

[7] Moreno, T., Querol, X., Alastuey, A., Minguillóon, M.C., Pey, J., Rodriguez, S., Miró, J.V., Felis, C. and Gibbons, W. (2007) Recreational Atmospheric Pollution Episodes: Inhalable Metalliferous Particles from Firework Displays. Atmospheric Environment, 41, 913-922. https://doi.org/10.1016/j.atmosenv.2006.09.019 
[8] Camilleri, R. and Vella, A.J. (2010) Effect of Fireworks on Ambient Air Quality in Malta. Atmospheric Environment, 44, 4521-4527. https://doi.org/10.1016/j.atmosenv.2010.07.057

[9] Wang, Y., Zhuang, G., Xu, C. and An, Z. (2007) The Air Pollution Caused by the Burning of Fireworks during the Lantern Festival in Beijing. Atmospheric Environment, 41, 417-431. https://doi.org/10.1016/j.atmosenv.2006.07.043

[10] Vecchi, R., Bernardoni, V., Cricchio, D., DAlessandro, A., Fermo, P., Lucarelli, F., Nava, S., Piazzalunga, A. and Valli, G. (2008) The Impact of Fireworks on Airborne Particles. Atmospheric Environment, 42, 1121-1132. https://doi.org/10.1016/j.atmosenv.2007.10.047

[11] Attri, A.K., Kumar, U. and Jain, V. (2001) Microclimate: Formation of Ozone by Fireworks. Nature, 411, 1015. https://doi.org/10.1038/35082634

[12] Kulshrestha, U., Rao, T.N., Azhaguvel, S. and Kulshrestha, M. (2004) Emissions and Accumulation of Metals in the Atmosphere Due to Crackers and Sparkles during Diwali Festival in India. Atmospheric Environment, 38, 4421-4425. https://doi.org/10.1016/j.atmosenv.2004.05.044

[13] Ravindra, K., Mor, S. and Kaushik, C. (2003) Short-Term Variation in Air Quality Associated with Firework Events: A Case Study. Journal of Environmental Monitoring, 5, 260-264. https://doi.org/10.1039/b211943a

[14] Wilkin, R.T., Fine, D.D. and Burnett, N.G. (2007) Perchlorate Behavior in a Municipal Lake Following Fireworks Displays. Environmental Science \& Technology, 41, 3966-3971. https://doi.org/10.1021/es0700698

[15] Shi, Y., Zhang, N., Gao, J., Li, X. and Cai, Y. (2011) Effect of Fireworks Display on Perchlorate in Air Aerosols during the Spring-Festival. Atmospheric Environment, 45, 1323-1327. https://doi.org/10.1016/j.atmosenv.2010.11.056

[16] Smith, R.M. and Dinh, V.D. (1975) Changes in Forced Expiratory Flow Due to Air Pollution from Fireworks: Preliminary Report. Environmental Research, 9, 321-331. https://doi.org/10.1016/0013-9351(75)90012-2

[17] Becker, J.M., Iskandrian, S. and Conkling, J. (2000) Fatal and Near-Fatal Asthma in Children Exposed to Fireworks. Annals of Allergy, Asthma \& Immunology, 85, 512-513. https://doi.org/10.1016/S1081-1206(10)62581-1

[18] Hirai, K., Yamazaki, Y., Okada, K., Furuta, S. and Kubo, K. (2000) Acute Eosinophilic Pneumonia Associated with Smoke from Fireworks. Internal Medicine, 39, 401-403. https://doi.org/10.2169/internalmedicine.39.401

[19] Murty, O. (2000) Diwali Toxicity. Journal of Forensic Medicine and Toxicology, 17, 23-26.

[20] Steinhauser, G., Sterba, J.H., Foster, M., Grass, F. and Bichler, M. (2008) Heavy Metals from Pyrotechnics in New Years Eve Snow. Atmospheric Environment, 42, 8616-8622. https://doi.org/10.1016/j.atmosenv.2008.08.023

[21] Godri, K.J., Green, D.C., Fuller, G.W., DallOsto, M., Beddows, D.C., Kelly, F.J., Harrison, R.M. and Mudway, I.S. (2010) Particulate Oxidative Burden Associated with Firework Activity. Environmental Science \& Technology, 44, 8295-8301. https://doi.org/10.1021/es1016284

[22] Kim, K.H., Sekiguchi, K., Kudo, S. and Sakamoto, K. (2011) Characteristics of Atmospheric Elemental Carbon (Char and Soot) in Ultrafine and Fine Particles in a Roadside Environment, Japan. Aerosol and Air Quality Research, 11, 1-12.

[23] Sarkar, S., Khillare, P.S., Jyethi, D.S., Hasan, A. and Parween, M. (2010) Chemical Speciation of Respirable Suspended Particulate Matter during a Major Firework 
Festival in India. Journal of Hazardous Materials, 184, 321-330. https://doi.org/10.1016/j.jhazmat.2010.08.039

[24] Arpacal-Centro Funzionale Multirischi (2017). http://www.cfd.calabria.it/index.php/dati-stazioni/dati-storici

[25] Statistiche I. Stat (2017). http://dati.istat.it/Index.aspx

[26] European Standards (2017). http://www.cen.eu/cen

[27] Xiao, Z.M., Zhang, Y.F., Hong, S.M., Bi, X.H., Jiao, L., Feng, Y.C. and Wang, Y.Q. (2011) Estimation of the Main Factors Influencing Haze, Based on a Long-Term Monitoring Campaign in Hangzhou, China. Aerosol and Air Quality Research, 11, 873-882.

[28] Turpin, B.J. and Huntzicker, J.J. (1995) Identification of Secondary Organic Aerosol Episodes and Quantitation of Primary and Secondary Organic Aerosol Concentrations during SCAQS. Atmospheric Environment, 29, 3527-3544.

https://doi.org/10.1016/1352-2310(94)00276-Q

[29] Cao, J., Lee, S., Ho, K., Zhang, X., Zou, S., Fung, K., Chow, J.C. and Watson, J.G. (2003) Characteristics of Carbonaceous Aerosol in Pearl River Delta Region, China during 2001 Winter Period. Atmospheric Environment, 37, 1451-1460. https://doi.org/10.1016/S1352-2310(02)01002-6

[30] Cavalli, F., Viana, M., Yttri, K.E., Genberg, J. and Putaud, J.P. (2010) Toward a Standardised Thermal-Optical Protocol for Measuring Atmospheric Organic and Elemental Carbon: The EUSAAR Protocol. Atmospheric Measurement Techniques, 3, 79-89. https://doi.org/10.5194/amt-3-79-2010

[31] Castro, L., Pio, C., Harrison, R.M. and Smith, D. (1999) Carbonaceous Aerosol in Urban and Rural European Atmospheres: Estimation of Secondary Organic Carbon Concentrations. Atmospheric Environment, 33, 2771-2781. https://doi.org/10.1016/S1352-2310(98)00331-8

[32] Turpin, B.J. and Huntzicker, J.J. (1991) Secondary Formation of Organic Aerosol in the Los Angeles Basin: A Descriptive Analysis of Organic and Elemental Carbon Concentrations. Atmospheric Environment. Part A. General Topics, 25, 207-215. https://doi.org/10.1016/0960-1686(91)90291-E

[33] Lim, H.J. and Turpin, B.J. (2002) Origins of Primary and Secondary Organic Aerosol in Atlanta: Results of Time-Resolved Measurements during the Atlanta Supersite Experiment. Environmental Science \& Technology, 36, 4489-4496. https://doi.org/10.1021/es0206487

[34] Cabada, J.C., Pandis, S.N., Subramanian, R., Robinson, A.L., Polidori, A. and Turpin, B. (2004) Estimating the Secondary Organic Aerosol Contribution to $\mathrm{PM}_{2.5}$ Using the EC Tracer Method Special Issue of Aerosol Science and Technology on Findings from the Fine Particulate Matter Supersites Program. Aerosol Science and Technology, 38, 140-155. https://doi.org/10.1080/02786820390229084

[35] Harrison, R.M. and Yin, J. (2008) Sources and Processes Affecting Carbonaceous Aerosol in Central England. Atmospheric Environment, 42, 1413-1423. https://doi.org/10.1016/j.atmosenv.2007.11.004

[36] Pio, C., Cerqueira, M., Harrison, R.M., Nunes, T., Mirante, F., Alves, C., Oliveira, C., de la Campa, A.S., Artínano, B. and Matos, M. (2011) OC/EC Ratio Observations in Europe: Re-Thinking the Approach for Apportionment between Primary and Secondary Organic Carbon. Atmospheric Environment, 45, 6121-6132. https://doi.org/10.1016/j.atmosenv.2011.08.045

[37] Dinoi, A., Cesari, D., Marinoni, A., Bonasoni, P., Riccio, A., Chianese, E., 
Tirimberio, G., Naccarato, A., Sprovieri, F., Andreoli, V., et al. (2017) Inter-Comparison of Carbon Content in $\mathrm{PM}_{2.5}$ and $\mathrm{PM}_{10}$ Collected at Five Measurement Sites in Southern Italy. Atmosphere, 8, 243. https://doi.org/10.3390/atmos8120243

[38] Baldi, M., Gaetani, M., Dalu, G. and Maracchi, G. (2008) Jetstream and Seasonal Anomalies in the Mediterranean. Bollettino Geofisico, a. XXXI, n. 1-4, gennaio-dicembre, 51-69.

[39] Baldi, M., Dalu, G., Maracchi, G., Pasqui, M. and Cesarone, F. (2006) Heat Waves in the Mediterranean: A Local Feature or a Larger-Scale Effect? International Journal of Climatology, 26, 1477-1487. https://doi.org/10.1002/joc.1389

[40] Da Silva, A.M., Young, C.C. and Levitus, S. (1995) Toward a Revised Beaufort Equivalent Scale. In: Diaz, H.F. and Isemer, H.-J., Eds., Proceedings International COADS Winds Workshop, NOAA-ERL, IFM (Kiel), 270-286.

[41] Sprovieri, F., Bencardino, M., Cofone, F. and Pirrone, N. (2011) Chemical Composition of Aerosol Size Fractions at a Coastal Site in Southwestern Italy: Seasonal Variability and Transport Influence. Journal of the Air \& Waste Management Association, 61, 941-951. https://doi.org/10.1080/10473289.2011.599267

[42] Parliament, E., of the Council (2008) Directive 2008/50/EC of the European Parliament and of the Council of 21 May 2008 on Ambient Air Quality and Cleaner Air for Europe.

[43] I-AMICA Monitoring Stations (2017). http://www.i-amica.it/i-amica/?pageid=1122

[44] Turpin, B.J., Huntzicker, J.J. and Hering, S.V. (1994) Investigation of Organic Aerosol Sampling Artifacts in the Los Angeles Basin. Atmospheric Environment, 28, 3061-3071. https://doi.org/10.1016/1352-2310(94)00133-6

[45] Pongpiachan, S., Kudo, S. and Sekiguchi, K. (2014) Chemical Characterization of Carbonaceous $\mathrm{PM}_{10}$ in Bangkok, Thailand. Asian Journal of Applied Sciences, 7, 325-342. 


\title{
Appendix A. Supplemental Section
}

\author{
lon: plotted from -10 to 40.00 \\ lat: plotted from 20.00 to $\mathbf{6 0 . 0 0}$ \\ lev: 925.00
}

t: averaged over Jul 292016 to Aug 42016

Mean hgt $\mathrm{m}$

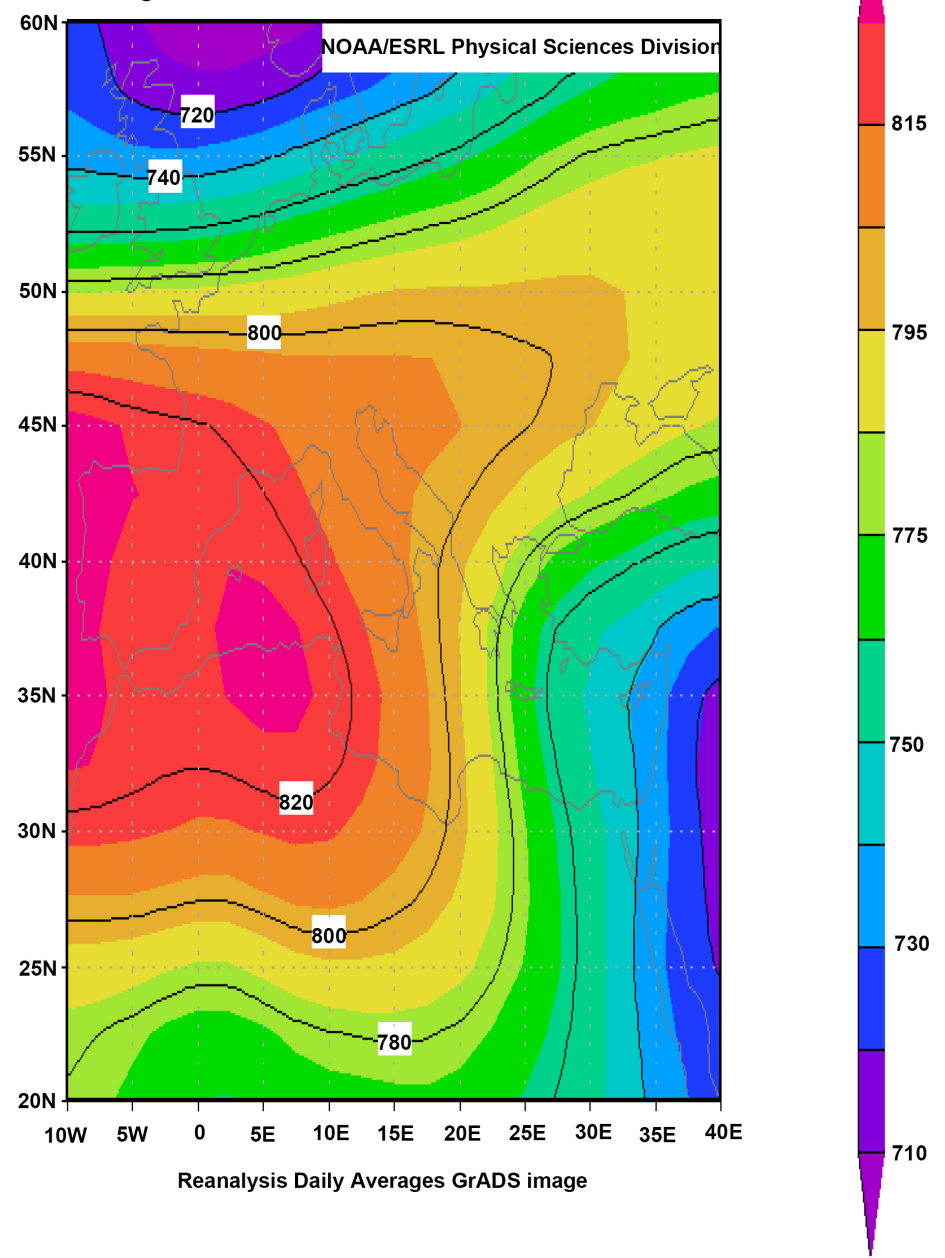

Figure A1. NCEP chart showing the geo-potential heights $(\mathrm{m})$ over the whole Mediterranean region and during the study period (from 29 Jun to 4 Aug). 


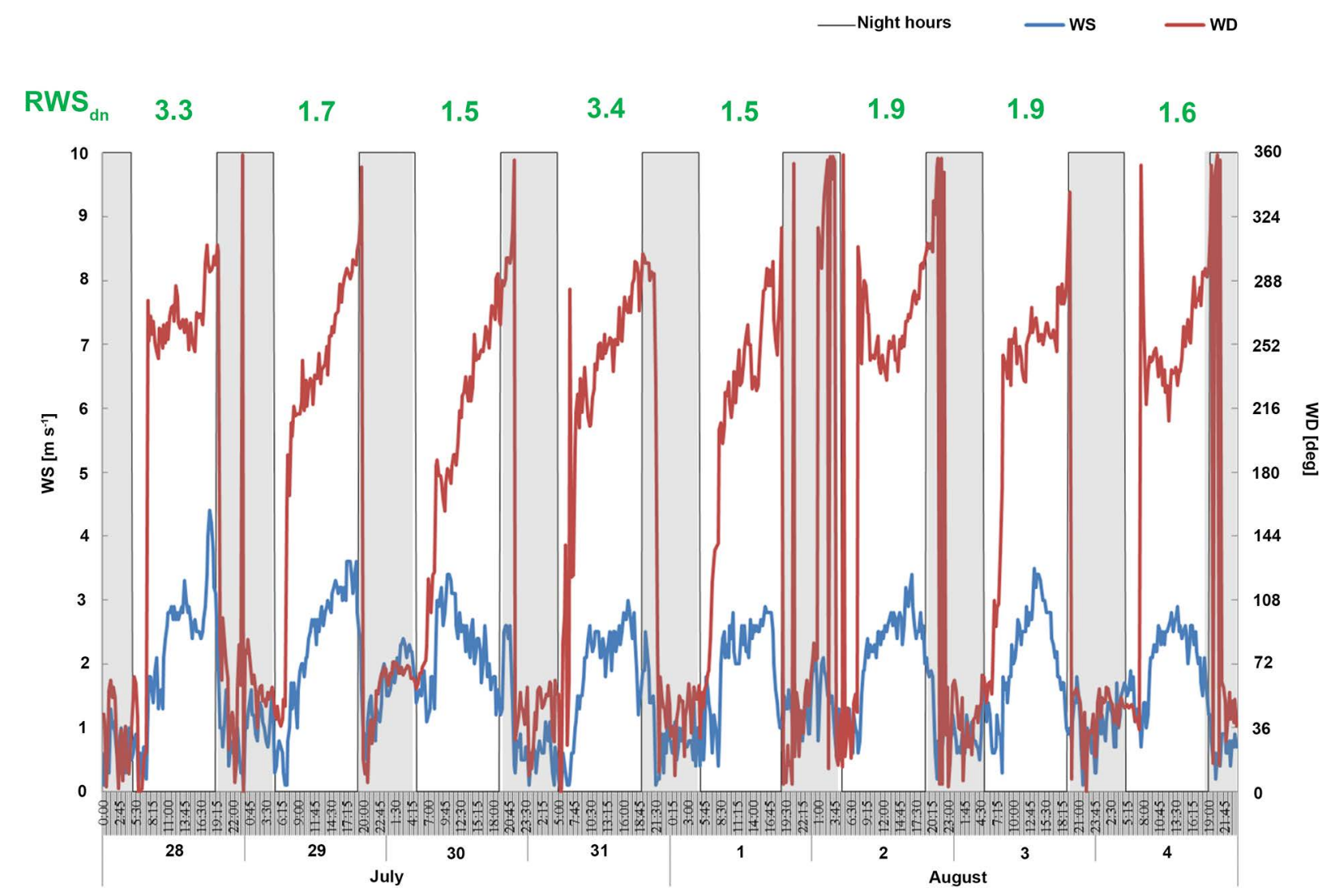

Figure A2. Wind Speed (WS-ms ${ }^{-1}$ ) and Wind Direction (WD-degree) over the study period with gray bars highlighting the night hours. The Ratio between diurnal and night mean values of Wind Speed (RWSdn) is also overwritten.

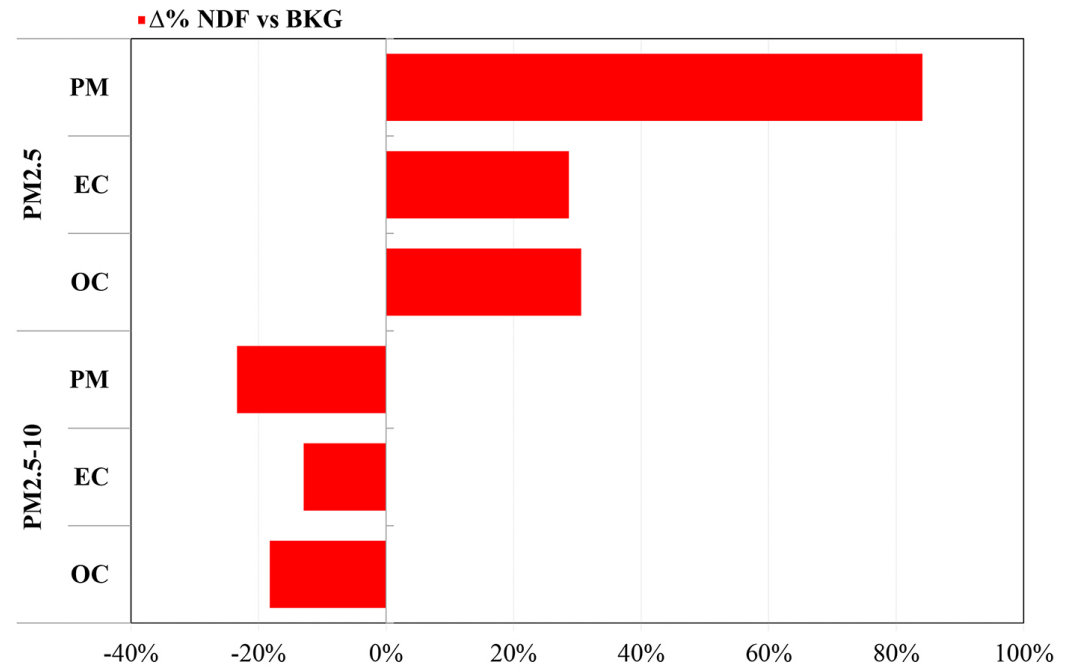

Figure A3. Percentage variation of $P M$, EC and OC levels recorded during NDF in respect with those observed at BKG, for Fine $\left(P M_{2.5}\right)$ and Coarse $\left(P M_{2.5-10}\right)$ size particle fractions. 


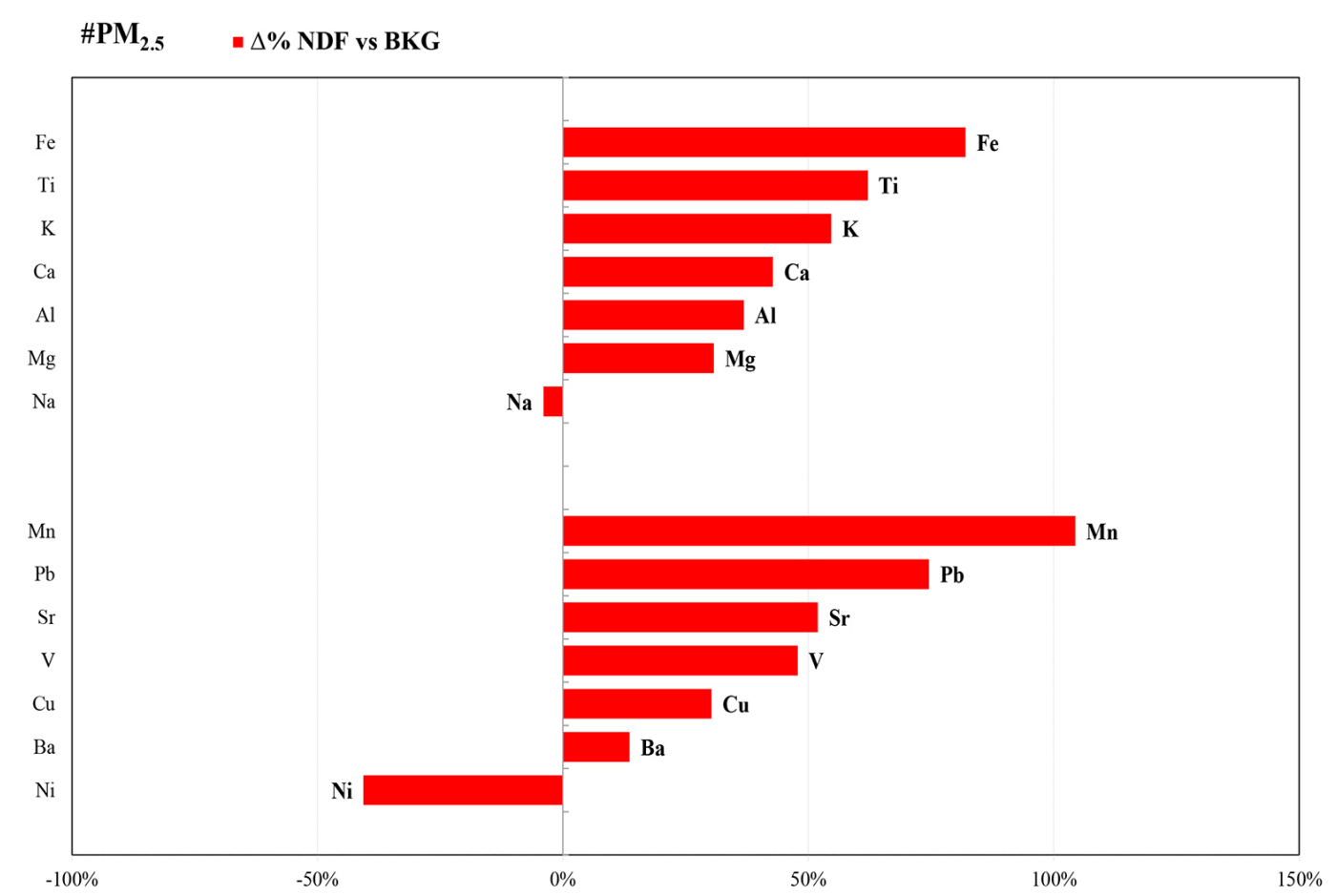

(a)

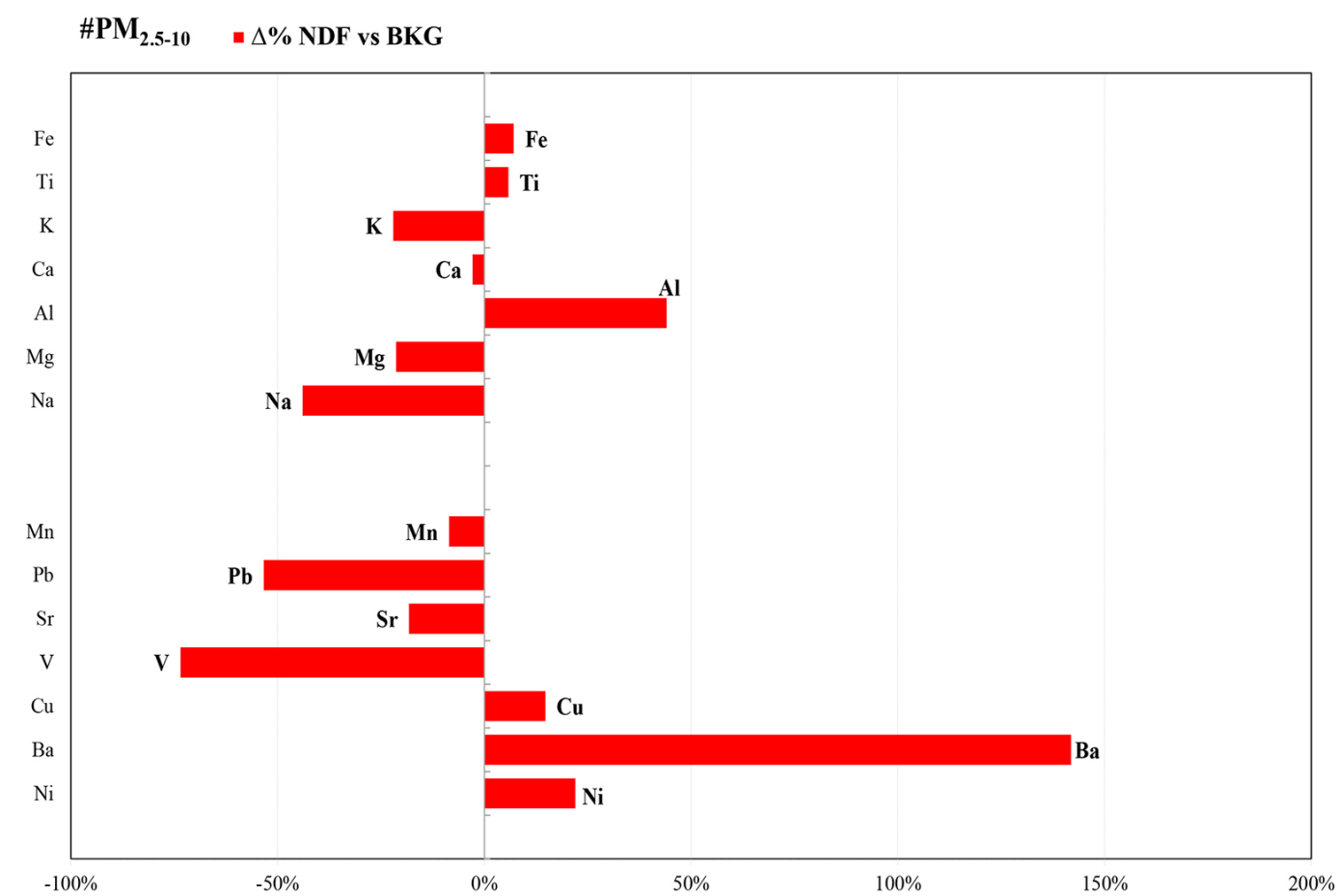

(b)

Figure A4. Percentage variation of each detected Major and Trace element level recorded during NDF in respect with that observed at $\mathrm{BKG}$, for Fine $\left(P M_{2.5}\right)$ and Coarse $\left(P M_{2.5-10}\right)$ size particle fractions. 